\title{
RNA Binding Protein RNPC1 Promotes Gastric Cancer Progression via Stabilizing the Aurora Kinase B mRNA
}

\section{Chunmei Ji}

First hospital of nanjing medical university

\section{Xu Zhang}

The first hospital of nanjing medical university

\section{Wentong Fang}

The first affiliated hospital of nanjing medical university

\section{Ling Meng}

The first affiliated hospital of nanjing medical university

\section{Xiaolong Wei}

Cancer hospital of shantou university medical college

Chen Lu ( $\nabla$ gzfylc@gmu.edu.cn )

First affiliated hospital of gannan medical university https://orcid.org/0000-0002-3422-9597

\section{Primary research}

Keywords: RNPC1, gastric cancer, oncogene, Aurora kinase B, mRNA stability

Posted Date: January 20th, 2021

DOI: https://doi.org/10.21203/rs.3.rs-148988/v1

License: (1) This work is licensed under a Creative Commons Attribution 4.0 International License. Read Full License 


\section{Abstract}

\section{Background}

RNPC1, was reported to act as a tumor suppressor by binding and regulating the expression of the target genes in various cancers. However, the role of RNPC1 on the gastric cancer and the underly mechanisms were still unclear.

\section{Methods}

Gastric cancer cells were stably transfected with lentivirus. Proliferation, migration, invasion, cell cycle in vitro as well as tumorigenesis in vivo were performed to assess the role of RNPC1. Quantitative real-time PCR, western blot and immunohistochemistry were used to detect the relation between RNPC1 and Aurora kinase B (AURKB). RNA immunoprecipitation(RIP), RNA electrophoretic mobility shift assay (REMSA), dual-luciferase reporter assay were employed to identify the direct binding sites of RNPC1 with AURKB mRNA. CCK-8 assay conducted to confirm the function of AURKB in RNPC1-induced growth promotion.

Results

High RNPC1 expression was found in gastric cancer tissues and cell lines, associated with high TNM stage. RNPC1 overexpression could significantly promote the proliferation, migration, invasion of gastric cancer cells. Knockdown of RNPC1 could impede gastric cancer tumorigenesis in nude mice. AURKB expression was positively related with RNPC1. RNPC1 binded to the 3'-untranslated region (3'-UTR) of AURKB directly and enhanced AURKB mRNA stability. AURKB could reversed the proliferation induced by RNPC1 in gastric cancer cells. RNPC1 resulted in mitotic defects, aneuploidy and chromosomal instability in gastric cancer cells, as AURKB did.

\section{Conclusion}

RNPC1 acted as an oncogene in gastric cancer by influencing cell mitosis by regulating AURKB mRNA stability, which may provide a potential biomarker and therapeutic target for gastric cancer.

\section{Introduction}

Gastric cancer is the fifth most common cancer and the third leading cause of cancer-related death worldwide [1, 2]. Although, surgery and following chemotherapy has been widely used for the treatment of gastric cancer,the prognosis of gastric cancer is still not ideal [3]. Thus, an improved and detailed understanding of the mechanisms underlying gastric cancer pathogenesis is urgently needed.

The RNA-binding proteins (RBPs) acted as master regulators of RBA biogenesis and metabolism. They were involved in many biological progress by regulating variou relative genes[4, 5]. The RNA-binding motif protein 38 (RBM38), also known as RNPC1 is located on chromosome 20q13.31. It belongs to the RNA 
recognition motif (RRM) family of RBPs, containing a putative RNA recognition motif, which shares a sequence similarity with the ones in Hu antigen R (HuR) and Musashi [6, 7]. RNPC1 is capable of regulating cell proliferation, cell cycle arrest and cell myogenic differentiation by affecting its target mRNAs stability $[8,9]$.

Altered expression of RNPC1 was found in various cancers. RNPC1 was originally recognized as an oncogene, and frequently found to be within the sites, which was amplified in breast cancer [10, 11], prostate cancer [9, 12], ovarian cancer[13], colorectal cancer [14, 15], chronic lymphocytic

leukemia[16], and dog lymphomas [17]. Recently, RNPC1 was reported to act actually as tumor suppressor in breast cancer[18, 19], colorectal cancer[20], acute myeloid leukemia[21] , non-small cell lung cancer[22], renal cell carcinoma[23], hepatocellular carcinoma[24] and T-cell malignancies[25] by in vitro or in vivo investigation. Meanwhile, RNPC1 also reported to have oncogenic potential in certain cancer. In dog lymphomas, RNPC1 played a oncogenic role in tumorigenesis by repressing p53 translation[17]. RNPC1 inhibits the expression of tumor suppressor miR-34a, function as on oncogene during hypoxia in nonsmall cell lung cancer(NSCLC).[26] In addition, Xiaowan Yu indicated that RNPC1 is not a tumor suppressor in advanced liver cancer[27]. These was consistent with the bioinformatics analysis results which indicated that the function of RNPC1 in various cancers may be multidimensional, RNPC1 was not just a tumor suppressor or promoter[28].Till now, the biologic functions of RNPC1 and related mechanism in human gastric cancer remain obscure.

Our previous study found that Aurora kinase B (AURKB) mRNA might be bound by RNPC1 directly by using RNA-immunoprecipitation and sequencing (RIP-Seq) [29]. AURKB, was one member of the Aurora kinase family, played a central role in mitotic processes[30, 31],[32]. Any errors in mitotic signaling pathways can result in uncontrolled proliferation, which is regarded as one of the cardinal characteristics of tumors [33-35]. AURKB play a importance role in tumor, abnormal expression of AURKB is closely related with tumorigenesis in human cells. It was reported that AURKB was highly expressed in some human tumors including non-small cell lung cancer, breast cancer, colorectal cancer, hepatocellular carcinoma, astrocytic tumor, germ cell tumor, thyroid cancer, gastric cancer and leukemia[36-40]. Meanwhile overexpression of AURKB is associated with poor prognosis.[32, 41]. Recently, it had reported that AURKB could promote gastric tumorigenesis[42].

In this study, we sought to explore the potential role and underlying mechanism of RNPC1 in gastric cancer progression. We found that RNPC1 was high expressed in gastric cancer tissues, compared to normal gastric tissue. The biological experiment evidenced that RNPC1 could promote gastric cancer cells proliferation, growth, migration, and invasion in vitro, and tumorigenesis in vivo. Moreover, we revealed that RNPC1 expression was positively related with AURKB, and RNPC1 could directly bind to the 3'-UTR of AURKB. Totally, we demonstrated that this oncogenic activity of RNPC1 in gastric cancer may be conducted by regulating AURKB mRNA stability.

\section{Materials And Methods}




\section{Bioinformatics analysis}

The RNA-sep data and a and corresponding clinicopathologic profiles of gastric cancer tissues samples and normal controls samples were obtained from The Cancer Genome Atlas (TCGA) database (http://gepia.cancer-pku.cn/index.html), and applied for analyzing the expression of RNPC1 in 408 gastric cancer tissues and 211 normal tissues.

\section{Cell culture and transfection}

The human gastric normal epithelial mucosa cell line (GES-1) and gastric cancer cell lines (MGC-823, MGC-803, SGC-7901) was provided by Prof. Daming Gao from the Shanghai Institute of Biochemistry and Cell biology, the Chinese Academy of Sciences. The MGC-823, MGC-803, SGC-7901 were cultured in RPMI 1640 medium (Gibco, USA) supplemented with 10\% fetal bovine serum (FBS, Gibco, USA), 1\% penicillin-streptomycin (Gibco, USA) solution in an incubator with humidified $5 \% \mathrm{CO}_{2}$ at $37^{\circ} \mathrm{C}$; while the GES-1 was cultured in DMEM medium (Gibco, USA); .

The gastric cancer cell lines were transfected with RNPC1 knockdown lentivirus (termed as shRNPC11,shRNPC1-2)『a scrambled control (termed as SCR), RNPC1 overexpress lentivirus termed as RNPC1) or a negative control (termed as NC); which performed as described previously[43]. The cells were seeded into 6-wells plates and infected with the lentivirus, when the cells were at $30 \%$ confluence, $5 \mu \mathrm{g} / \mathrm{ml}$ polybrene was added into the 6 -wells plates to enhance the infection efficiency. Then puromycin $(3 \mu \mathrm{g} / \mathrm{ml})$ was used to select the stable transfected gastric cancer cells. Western blotanalysis and quantitative real-time polymerase chain reaction (qRT-PCR) were applied to determine the efficiency of transfection.

The AURKB was knockdown with small interfering RNAs (siRNA) (genpharma, China) in gastric cancer cell lines. The siRNA sequences was shown in Supplementary Table 2. The cells were transfected with about $10 \mathrm{~nm}$ siRNA or controls with lipofectamine 2000 transfection reagent (Invitrogen, USA) for 24h according to the manufacturer's instruction.

\section{Western blot}

Western blot analysis was performed as described previously[43]. The primary antibodies used were RNPC1 (Santa Cruz, USA, sc365898), aurora b(abcam, USA, ab45145), cyclin A2(abcam, USA, ab181591), cyclin D1(abcam, USA, ab205718) , cyclin E1(abcam, USA, ab71535). the secondary antibodies were purchased from cell signaling technology. The intensity of the bands was determined using densitometric analysis. $\beta$-actin antibody (Abcam,USA) was used to as control for normalization.

\section{RNA extraction, reverse transcription and qRT-PCR}

Total RNA was extracted from cells using Trizol reagent (Invitrogen, USA) and cDNA was synthesized using Primescript RT Reagent (TaKaRa, China) following manufacturer's instructions. The qRT-PCR was performed on StepOne Plus Real-Time PCR system (Applied Biosystems, USA). $\beta$-actin was amplified as 
an internal standard. Each sample was replicated three times and the data analyzed using the $2^{-\triangle \triangle C T}$ method.The detail PCR primers used were shown in Supplementary table 2.

\section{CCK-8 assay}

The 5000 gastric cancer transfected cells were seeded into 96 -well plates. Cell proliferation was documented at $0,24,48,72$ and $96 \mathrm{~h}$ after seeding. When measured the cell proliferation, the medium in each well was replaced with $100 \mu \mathrm{l}$ fresh medium containing $10 \%$ CCK-8, and the cells were incubated for $1 \mathrm{~h}$. The absorbance was measured by microplate reader (Biotek-Eon, Biotech, USA) at $450 \mathrm{~nm}$.

\section{Colony formation assay}

The transfected gastric cancer cells (1000 cells/well) were seeded into six-well plates and incubated in 1640 medium with $10 \%$ FBS. After about 2 weeks, colonies were fixed with methanol for 10 min, and then stained with $0.1 \%$ crystal violet (Beyotime, China). The colonies were imaged and counted.

\section{EdU assays}

The proliferation of RNPC1 overexpressed and knockdown gartric cancer cell lines were evaluated with the BeyoClick ${ }^{\mathrm{TM}}$ EdU cell proliferation kit with Alexa Fluor 555 (\#C0075S, Beyotime, Shanghai, China) according to the manufacturer's protocol. The cells were seeded into six-well plates and incubated overnight with $5 \% \mathrm{CO} 2$ at $37^{\circ} \mathrm{C}$. Then $1 \mathrm{ml} \mathrm{EdU}(20 \mu \mathrm{M})$ was added to the culture medium then incubated for 2 hours. The cells were fixed with $4 \%$ paraformaldehyde for 15 minutes, the washed with PBS containing 3\% BSA for 3 times. The PBS with $0.3 \%$ Triton X-100 PBS used to permeabilize the nuclear membrane for 15 minutes at room temperature. Finally, cells were stained using a BeyoClick ${ }^{\mathrm{TM}}$ EdU cell proliferation kit with Alexa Fluor 488(\#C0071S, Beyotime, Shanghai, China) according to the manufacturer's protocol.

\section{Wound healing assay}

The transfected gastric cancer cells were cultured in 6-well plates until 100\% confluence. The cell layer was scratched using a 200- $\mu$ l pipette tip and the loose cells were washed away with phosphate-buffered saline (PBS, pH 7.4), and the old media was replaced with the fresh media. Images of wound healing were taken after $24 \mathrm{~h}$. The distance of the wound was measured in 6 random selected microscopic fields (100x) for each condition and time point $(0,24 \mathrm{~h})$.

\section{Transwell assays}

The transwell assays were performed with transwell chamber (Millipore, NY, USA). For cell invasion assays, $\mathrm{BD}$ Matrigel ${ }^{\mathrm{TM}}$ basement membrane matrix was added to the upper chamber for one night at $37^{\circ} \mathrm{C}$. In transwell assays with or without Matrigel, $5 \times 10^{4}$ cells cells were re-suspended in serum-free medium and added into top compartment, and medium containing $10 \%$ FBS was added to the bottom 
compartment. After $24 \mathrm{~h}$, the methanol and crystal violet were used for fixation and stained of cells. The number of migrating and invading cells was counted under 200x magnification(Olympus,Japan).

\section{Cell cycle analysis}

Cells were collected, and fixed in ethanol at $-20^{\circ} \mathrm{C}$ for overnight. Then cells stained with propidium iodide (PI) by the cycletest plus DNA reagent kit (BD Biosciences, USA) at room temperature for 30 min and then measured by flow cytometry (Guava, BD Biosciences, USA). The ratios of cells in the G1, S, G2 phases were analyzed.

\section{Tumorigenesis in nude mice}

Female BALB/C nude mice (4-6 weeks old, 18-22g) were obtained from Model Animal Research Center of Nanjing University (Nanjing, China). All mice were feeding in the animal facility. The animal studies were performed in accordance with the institutional ethics guidelines for animal experiments, which was approved by the animal management committee of Nanjing Medical University. The mice were randomly allocated into two groups and injected with SGC-7901-shRNPC1 cells and SGC-7901-SCR cells $\left(1 \times 10^{7}\right.$ cells), respectively. The tumor volume $(V)$ was monitored by measuring the width $(W)$ and length $(L)$ with a caliper every 2 days and the tumor volume was calculated using the formula $V=\left(W^{2} \times L\right) / 2$. The mice were sacrificed after 3 weeks and checked for final tumor weight.

\section{Actinomycin D assay}

The stably transfected gastric cancer cell lines were treated with $5 \mu \mathrm{g} / \mathrm{ml}$ actinomyclin $D($ Act $D$ ) for 0,1 , 2, 4, 6, $8 \mathrm{~h}$. Total RNAs were harvested, and then subjected to qRT-PCR analysis. The relative quantification of AURKB transcript was calculated by the $2^{-\Delta \Delta C t}$ method and normalized based on $\beta$ actin. Then the relative half-life of AURKB was calculated.

\section{RNA immunoprecipitation (RIP)}

The transfected gastric cancer cell lines were lysed with RNA immunoprecipitation lysis buffer (Millipore, USA) and then incubated with $5 \mu \mathrm{g}$ of rabbit polyclonal anti-RNPC1 (Santa Cruz Biotechnology, USA) or nonimmunized rabbit IgG at $4^{\circ} \mathrm{C}$ overnight. The RNA-protein immunocomplexes were brought down by protein $A / G$ magnetic beads, followed by RNA purification. After that, the purified RNA was subjected to RT-PCR and qRT-PCR. The primers to detect human AURKB, IgG and human antigen R (HuR) mRNA expressions were the same as those described previously[43].

\section{RNA electrophoretic mobility shift assay (REMSA)}

The recombinant RNPC1 proteins were expressed and purified as previously describe ${ }^{41,42}$. To generate REMSA probes, regions in AURKB mRNA 3'-UTR was amplified by PCR with primers including T7 (5'TAATACGACTCACTATAGGG-3'). The primers for AURKB probes were showed in Supplementary table 2. Biolabelled RNA probes were made from in vitro transcription with a MEGA shortscript Kit (Ambion, 
Waltham, MA, USA) in the presence of biotin-16-UTP (Roche) according to the manufacturer's instruction. The REMSA was performed as previously with some modification $(27,40)$ with the LightShift Chemiluminescent RNA EMSA Kit (Thermo, Waltham, MA, USA).

\section{Dual-Luciferase reporter assay}

The RNPC1 overexpress (RNPC1) and the control (NC) gastric cancer cells were cultured in the 24 well plates. Then cells were cotransfected with $5 \mathrm{ng}$ plasmids that containing AURKB 3'-UTR, AURKB-mutant 3'-UTR or empty vector with Lipofectamine3000 (Invitrogen, USA). We mutated all U residues to $G$ in the AURKB-mutant 3'-UTR . Twenty-four hours after transfection, luciferase activity was measured with the dual luciferase kit according to manufacturer's procedure (Promega, USA). The fold change in relative luciferase activity is a ratio of the luciferase activity induced by RNPC1 divided by that induced by NC. The sequence of the AURKB 3'-UTR was same as the REMSA.

\section{IC50 determination}

The cells were seeded in 96 -well platewith5000 cells/well, and incubated for $24 \mathrm{~h}$. Then the cells were treated with increasing concertrations of AURKB inhibitors AZD1152-HQPA or hesperadin(MedChem Express,shanghai, china ) for $48 \mathrm{~h}$. The cell viability was determined with CCK-8 assay and the concentration that induced $50 \%$ growth inhibition (IC50) were calculated.

\section{IHC staining}

Eighty-five gastric cancer tissues and 26 tumor-adjacent normal tissues were obtained from gastric cancer patients who underwent resection surgery at the Cancer Hospital of Shantou University Medical College, Shantou, Guangdong,China. This study was approved by the Ethics Committee Cancer Hospital of the Cancer Hospital of Shantou University Medical College. The specimens were assessed by immunohistochemistry $(\mathrm{IHC})$ and the diagnosis was verified by histopathological examination. IHC staining was performed according to the procedure described previously[43].The same tissue samples were stained with the monoclonal antibodies against RNPC1 (Santa Cruz) and aurora b(abcam, USA). The images were observed under $100 \times$ magnifications under a microscope(Olympus, japan).

\section{Immunofluorescence}

The immunofluorescence were performed with immunol fluorence staining kit (Beyotime, China) according to the manufacturer's protocol. The cells were plated in the laser copolymerized petri dish, and fixed with immunol staining fix solution. After being permeabilized with $0.1 \%$ triton X-100 and blocked with immunol staining blocking buffer, the cells were incubated with primary antibody (anti-a-tubulin antibodies 1:1000, Sigma-Aldrich, USA; anti-y-tubulin 1:50, abcam, USA) at $4^{\circ} \mathrm{C}$ overnight. Following incubated with rabbit goat anti-rabbit IgG-FITC or mouse goat anti-mouse IgG-FITC (Cell Signaling Technology, 1:600) in the dark for $1 \mathrm{~h}$ and counterstained with 46-diamidino-2-phenylindole (DAPI) for 10 min. Fluorescent images were captured by a confocal laser microscope (Olympus, Japan). 


\section{Statistical analysis}

Statistical analysis was performed with SPSS 20 software and GraphPad Prism 6. The differences between two independent groups were analyzed using Student's $t$ test. A $P$-value $<0.05$ was considered to represent a statistically significant difference.

\section{Results}

\section{RNPC1 was elevated in gastric cancer tissues and cells}

The expression of RNPC1 was investigated in both gastric cancer tissues and normal stomach tissues based on the RNA-sep data obtained from TCGA database. The results showed that RNPC1 was obviously up-regulated in gastric cancer tissues $(n=408)$ compared with the normal stomach samples $(n$ $=211$, Fig. 1A). Then the expression of RNPC1 in normal stomach and gastric cancer cell lines were quatified by western blot and qRT-PCR analysis. It showed that the protein and mRNA expression of RNPC1 were upregulated in gastric cancer cell lines (MGC-823, SGC-7901, MGC-803) compared with that in normal stomach(GES-1) cell line(Fig. 1B, C).

Moreover, the IHC analysis indicated that RNPC1 showed a low expression in most of the 26 tumoradjacent normal tissues $(n=19,73.07 \%, p=0.034)$, while $43(58.59 \%)$ of the 85 gastric cancer tissues showed a high RNPC1 expression(Table 1).The result was consistent with the Bioinformatics analysis above(Fig 1A), they all indicated that RNPC1 was upregulated in gastric cancer tissues. RNPC1 expression was positively associated with TNM stage $(p=0.046)$. There was no significant correlation between RNPC1 expression and gender, pathological grade, age, lymph node metastasis.

\section{RNPC1 promoted the proliferation of gastric cancer cells in vitro}

The western blot and qRT-PCR (Fig. 2A,B) results showed that the stably transfected RNPC1 knockdown and overexpress gastric cancer cell lines (MGC-803,SGC-7901) were estabilished. Then, the effect of RNPC1 on the viability of gastric cancer cells were evaluated by CCK-8 kit. The results showed that the viability of gastric cancer cells MGC-803 and SGC-7901 were significantly inhibited while knockdwon RNPC1 (Fig. 2C). While, the overexpress RNPC1 significantly increased the viability of gastric cancer cells (Fig. 2D). Meanwhile, the RNPC1 was overexpressed in GES-1 cell (Supplementary Figure 1A,B). It showed that RNPC1 also significantly increased the viability of GES-1 cell (Supplementary Figure 1C).

RNPC1 knockdown reduced colony formation ability of MGC-803 and SGC-7901 (Fig. 2E), while RNPC1 overexpress enhanced (Fig. 2F). Further, EdU assay performed to detect the role of RNPC1 on the proliferation in MGC-803 and SGC-7901. The results showed that RNPC1 siginifantly increased the percentage of EdU positive cells in MGC-803 and SGC-7901 cells(Fig.2G,H).

The cell cycle analysis indicated that RNPC1 knockdown could increase the percentage of cells in G1 phase in gastric cancer cells (Fig.3A,B). On the contrary, the cells distributed in $\mathrm{G} 1$ phase were decreased 
in the RNPC1 overexpression gastric cancer cells (Fig. 3C,D). All results indicated that RNPC1 improved the proliferation ability of gastric cancer cells by promoting $\mathrm{G} 1 / \mathrm{S}$ transition.

Cell cycle cyclins change with cell cycle's progression and thus pattern of cyclins could reflect the specific cell-cycle stage. The protein expression of cell cycle phase-specific cyclins, including cyclin A2, cyclin D1,cyclin E1 in RNPC1 overexpress and knockdown gastric cancer cells were investigated.We observed that RNPC1 could up-regulate the expression levels of cyclin D1,cyclin E1; while knockdown RNPC1 downregulated (Fig.3E). In addition, there was no obviously change of cyclin A2 observe in RNPC1 overexpression and knockdown gastric cancer cells. The results suggested that RNPC1 postively mediated cyclin D1, cyclin E1, promoting G1/S transition.

\section{RNPC1 promote the migration and invasion of gastric cancer cells}

The wound healing assay showed that RNPC1 knockdown could decrease the migrated distance of gastric cancer cells MGC-803 and SGC-7901(Supplementary Figure 2A); while RNPC1 overexpress increased the migrated distance compared with the NC and the empty vector(WT) group (Supplementary Figure 2B). Meanwhile, the transwell assay showed that RNPC1 knockdown decreased the ability of migration and invasion in gastric cancer cells MGC-803 and SGC-7901 significantly (Supplementary Figure 2C). RNPC1 overexpression resulted in a significant increase in the migratory and invasive capabilities of gastric cancer cells (Supplementary Figure 2D). All these findings indicated that RNPC1 could improve the migratory and invasive ability of gastric cancer cells MGC-803 and SGC-7901.

\section{RNPC1 promoted gastric cancer tumorigenesis in nude mice in vivo}

The SGC-7901-shRNPC1 and SGC-7901-SCR cells were injected into the nude mice. The tumor volumes were measured every two days, and the tumors derived from cells after injection for three weeks(Fig. 4A). The mice injected with SGC-7901-shRNPC1 gastric cancer cell formed smaller tumor both in volume and weight, compared to the SGC-7901-SCR cells (Fig. 4B, C). These data indicated that RNPC1 knockdown could inhibit tumorigenesis in vivo.

\section{RNPC1 was positively related with AURKB in gastric cancer cells and tissues}

The protein and mRNA levels of AURKB in RNPC1 overexpression and knockdown gastric cancer cells were measured.There was a positive correlation between AURKB and RNPC1(Fig 5A,5B). Moreover, the expression of AURKB was also positively related with RNPC1 in the GES-1, MGC-803, SGC-7901 cell lines (Fig $5 \mathrm{C}$ ). Furthermore, the IHC analysis also indicated that the expression of AURKB was obviously higher in RNPC1 positive gastric cancer tissues, while RNPC1 negative gastric cancer tissues showed lower expression of $\operatorname{AURKB}(p=0.021$, Table 1$)$. The representative images of AURKB and RNPC1 expression were showed in Figure 5D. All these data indicated that RNPC1 could positively affect AURKB expression in gastric cancer cells and tissues.

\section{AURKB promoted the proliferation of gastric cancer cells in vitro}


The oncogene role of AURKB in gastric cancer cells was confirmed in this article which was consistent with the results recently reported by Min Nie et al[42]. The ICH result showed that AURKB was upregulated in most gastric cancer tissues $(51 / 85,60 \%$, Supplementary Table 1$)$, while down-regulated in most tumor-adjacent normal tissues (22/26, 84.62\%). The AURKB expression was positively associated with TNM stage $(p=0.038)$ and lymph node metastasis $(p=0.021)$. Moreover, the AURKB was knockdown in gastric cancer cell(Supplementary Figure 3A,B); it decreased the viability (Supplementary Figure 3C,D) and migration ability (Supplementary Figure 3E) of gastric cancer cells.In total,AURKB play an oncogene role in gastric cancer cell.

\section{RNPC1 could bind to AURKB transcript directly and enhance its mRNA stability}

The Act D assay showed that RNPC1 knockdown could significantly decrease the half-life of AURKB mRNA while RNPC1 overexpress increased. In MGC-803 cell the half-life of AURKB mRNA decreased from $2.91 \mathrm{~h}$ to $1.95 \mathrm{~h}$ after knockdown RNPC1, while in SGC-7901 the half-life decreased from $3.27 \mathrm{~h}$ to 1.93h(Fig. 6A). After overexpression of RNPC1, the half-life of AURKB mRNA was $3.77 \mathrm{~h}$ to $5.56 \mathrm{~h}$ in MGC803 cell, and $2.34 \mathrm{~h}$ to $>8.0 \mathrm{~h}$ in SGC-7901, respectively (Fig.6B). Together, these data demonstrated that RNPC1 could enhance the stability of AURKB mRNA.

RIP assay was used to investigate whether RNPC1 physically associated with AURKB mRNA. Then the RTPCR and qRT-PCR results showed that AURKB transcript was present in RNPC1, but not in the control IgG immunocomplexes(Fig.6C). HuR transcripts were positive controls as they had previously been deciphered to form immunocomplexes with RNPC1 $[8,38]$. As a negative control, RNPC1 was unable to bind to $\beta$-actin mRNA. It indicated that RNPC1 could bind to AURKB mRNA directly.

REMSA was performed to detect the direct binding site of RNPC1 in AURKB mRNA with the bio-UTPlabelled probe. As the length of the 3 '-UTR of the AURKB mRNA was just $139 \mathrm{bp}$, we just created one probe including the whole sequence of the AURKB 3'-UTR. The RNPC1 protein was able to form RNA-protein complexes with the probe we selected. It indicated that RNPC1 could bind to AREs region of AURKB mRNA 3'-UTR(Fig 6D).

The dual-luciferase assay was used to functionally confirm that the $3^{\prime}-$ UTR were required for RNPC1 binding to the AURKB.The luciferase plasmids with regions including AURKB 3'-UTR, mutated AURKB 3'UTR or empty vector (Pezx-FR02) were constructed. The luciferase activity for the reporter carrying AURKB 3'-UTR was increased by RNPC1, compared with the control (empty vector) (Fig.6E). While, there were no obvious difference in the mutated AURKB 3'-UTR group and control group. These data suggested that RNPC1 could bind to the 3 '-UTR of AURKB mRNA.

\section{AURKB interference reversed the proliferation induced by RNPC1 in gastric cancer cells.}

To explore the role of AURKB in the RNPC1 regulating cell proliferation, the RNPC1 overexpression and the control gastric cancer cells were treated with the AURKB inhibitor(AZD1152-HQPA and hesperadin) for 48 hours and determined by CCK-8 assay. Firstly, the concentration of AZD1152-HQPA and hesperadin that 
induced $50 \%$ growth inhibition(IC50\%) of gastric cancer cells were explored(Fig. 7A,B). Then the The gastric cancer SGC-7901 cells were treated with $13 \mu \mathrm{M}$ AZD1152-HQPA and $295 \mathrm{nM}$ hesperadin, while the MGC-803 cells treated with $35 \mu \mathrm{M}$ AZD1152-HQPA and $425 \mathrm{nM}$ hesperidin, respectively. CCK-8 assay showed the proliferation promoting effect of RNPC1 was decreased when the gastric cancer cells treated with AURKB inhibitors (Fig. 7C,D).

Moreover, the gastric cancer cells(MGC-803 and SGC-7901) were transfected with AURKB siRNA (AURKBS1, AURKB-S2)to further explore if RNPC1 drives cell proliferation through an AURKB-dependent mechanism. The relative OD value were measured at 48h after the RNPC1 overexpress gastric cancer cells tranfected with or without siRNA by CCK-8 assay. The results showed that the proliferation of RNPC1 overexpression was reduced(Fig 7E,F). So we indicated that AURKB totally reversed the proliferation induced by RNPC1 in gastric cancer cells.

\section{AURKB and RNPC1 were involved in the abnormal mitosis in gastric cancer cells}

Moreover, the polyploidy induced by RNPC1 and AURKB was further investigated by laser confocal microscope. The cells were stained with anti-a-tubulin, anti-y-tubulin and DAPI for microtubules and chromosome, respectively.Compared with control cells, cells treat with the AURKB siRNA were leading to less formation of polyploidy. In the control group, cells produced more multipolar spindle or centrosome, and the cells centrosome became fuzzy accompanied by the increasing of centrosome volume or the formation of multinucleated cells (Fig. 8). The same phenomena also found in the RNPC1 knockdown gastric cancer cells. And the cell cycle analysis also showed that there was an accumulation of cells at G2/S phase in the gastric cancer cells compared with the RNPC1 knockdown gastric cancer cells (Fig. $3 A, B)$.

\section{Discussion}

The RNA binding protein RNPC1 played pivotal roles in regulating cell proliferation, cell cycle arrest, and cell myogenic differentiation[8, 44]. It was also involved in many tumors progress. In the present study, we determined the biological effects of RNPC1 in gastric cancer and explored the potential underlying mechanism. It showed that RNPC1 could promote the proliferation, invasion, migration, tumorigenesis of gastric cancer in vitro and vivo, indicating that RNPC1 might play as an oncogene in gastric cancer. In addition, RNPC1 could increase the growth of normal stomach GES-1 cells. It was consistent with the result of bioinformatics analysis with TCGA database and the phenomenon that RNPC1 was amplified in gastric cancer. Reviewing the literature, RNPC1 mainly acted as tumor suppresser in various human cancers by in vitro or in vivo investigation[9-16]. However, some controversial results existed, RNPC1 might be overexpressed in some cancers just like dog lymphomia [17], NSCLC under hypoxic stress in vitro[26], and in early liver cancer [27]. All these suggested that the function of RNPC1 in cancer may be multidimensional [28].

The underlying mechanisms of RNPC1 in the process of tumors may be due to its stabilizing effect on mRNA of oncogenes or tumor suppressors. For example, RNPC1 can regulate biological processes by 
binding and stabilizing the mRNA of p21[45], p73[46], Hu antigen-R (HuR) $[45,47]$ and macrophage inhibitory cytokine-1 (MIC-1)[48], Zonula occludens-1 (ZO-1)[49], PTEN[25, 29] (phosphatase and tensin homolog gene on chromosome 10), estrogen receptor (ER)[43], and progesterone receptor (PR) [50] or by binding to the mRNAs of p63[51-54], c-myc[55], murine double minute-2 (MDM2)[56],and p53[25] and mediating the decrease in the mRNA levels. In our previous study, we defined thatAURKB was the targeted gene of RNPC1 by RIP-Seq [29]. We further found that the expression of RNPC1 was positively related with AURKB in gastric cancer by IHC, western blot and qRT-PCR. Moreover, RNPC1 could enhance AURKB mRNA stability by extending its half-life in gastric cancer cells. The RIP ,REMSA, luciferase activity assay found that RNPC1 could bind to the 3'-UTR of AURKB mRNA directly. All these results confirmed that RNPC1 could regulate the AURKB expression in gastric cancer by binding to the 3 '-UTR of AURKB mRNA directly and enhance its stability.

AURKB plays a central role in correcting kinetochore attachment errors. The AURKB was reported to overexpress in gastric cancer tisusses, and prometes gastric cancer progression. In the present study, we also confirmed that AURKB function as an oncogene in gastric cancer cells. We found that knockdown AURKB or using the AURKB inhibitors could decrease the growth of gastric cancer cells induced by RNPC1. It seemed that the cells proliferation promoting activity of RNPC1 in gastric cancer cells was due to the regulation of AURKB. DNA aneuploidy, which is characterized by cells containing an abnormal number of chromosomes, is closely associated with carcinogenesis and malignant progression, and acts as a hallmark of cancer[57-59]. Several studies found that overexpression of AURKB might contribute to DNA aneuploidy in gastric cancers by promoting chromosomal instability $[35,60]$. In the present study, we also found that RNPC1 resulted in mitotic defects, aneuploidy and chromosomal instability in gastric cancer cells, as AURKB did.These results further support that RNPC1 play a oncogene role in gastric cancer mainly by regulating AURKB.

In conclusion,we indicated that RNPC1 significantly increased in gastric cancer tissues, and promoted gastric cancer cells proliferation, migration, invasion and tumorigenesis in vitro and vivo.We evidenced that RNPC1 played as an oncogene in gastric cancer by influencing cell mitosis by regulating AURKB mRNA stability.We believe that RNPC1 may be a promising therapeutic target for human gastric cancer.

\section{Abbreviations}

RBM38: RNA-binding motif protein 38; AURKB: Aurora kinase B; RBPs:RNA-binding proteins; HuR: Hu antigen R; 3'-UTR: 3'-untranslated region;

PI: propidium iodide; Act D: Actinomyclin D; IHC: Immunohistochemistry; RIP: RNA immunoprecipitation; RIP-Seq: RNA-immunoprecipitation and sequencing; siRNA: small interfering RNA; MDM2: Mouse double minute 2 homolog; DAPI: 46-diamidino-2-phenylindole; PTEN:phosphatase and tensin homolog gene on chromosome; ER: estrogen receptor; PR: progesterone receptor.

\section{Declarations}


Acknowledgements

We would like to thank the Prof. Daming Gao from the Shanghai Institute of Biochemistry and Cell biology for providing the cell lines.

\section{Author contributions}

$\mathrm{CMJ}$, and XZ, WTF carried out the most experiments and drafted the manuscript; XLW contributed to the immunohistochemistry experiments. XZ performed the RIP assay. CMJ and WTF were involved in the statistical analysis. LM, XLW and CL managed the experimental design, reviewed the manuscript. All authors read and approved the final version of the manuscript.

\section{Funding}

The author(s) disclosed receipt of the following financial support for the research, authorship, and/or publication of this article: This work was supported by Tian Qing hospital pharmacy foundation of Jiangsu(Q2018008).

\section{Availability of data and material}

The data generated or analysed during this study are included in in this article.

\section{Ethics approval and consent to participate}

The study was approved by the Ethics Committee Cancer Hospital of the Cancer Hospital of Shantou University Medical College.

\section{Consent for publication}

The authors agrees to publication in the journal.

\section{Conflict of interest}

The authors declare no conflict of interest.

\section{References}

1. Siegel R, Naishadham D, Jemal A: Cancer statistics, 2013. CA: a cancer journal for clinicians 2013, 63(1):11-30.

2. de Mestier L, Lardiere-Deguelte S, Volet J, Kianmanesh R, Bouche O: Recent insights in the therapeutic management of patients with gastric cancer. Digestive and liver disease : official journal of the Italian Society of Gastroenterology and the Italian Association for the Study of the Liver 2016, 48(9):984-994.

3. He W, Tu J, Huo Z, Li Y, Peng J, Qiu Z, Luo D, Ke Z, Chen X: Surgical interventions for gastric cancer: a review of systematic reviews. International journal of clinical and experimental medicine 2015, 
8(8):13657-13669.

4. Bish R, Vogel C: RNA binding protein-mediated post-transcriptional gene regulation in medulloblastoma. Molecules and cells 2014, 37(5):357-364.

5. Kim MY, Hur J, Jeong S: Emerging roles of RNA and RNA-binding protein network in cancer cells. BMB reports 2009, 42(3):125-130.

6. Zhang J, Xu E, Chen X: Regulation of Mdm2 mRNA stability by RNA-binding protein RNPC1. Oncotarget 2013, 4(8):1121-1122.

7. Ganaie SS, Chen AY, Huang C, Xu P, Kleiboeker S, Du A, Qiu J: RNA Binding Protein RBM38 Regulates Expression of the 11-Kilodalton Protein of Parvovirus B19, Which Facilitates Viral DNA Replication. Journal of virology 2018, 92(8).

8. Shu L, Yan W, Chen X: RNPC1, an RNA-binding protein and a target of the p53 family, is required for maintaining the stability of the basal and stress-induced p21 transcript. Genes \& development 2006, 20(21):2961-2972.

9. Bar-Shira A, Pinthus JH, Rozovsky U, Goldstein M, Sellers WR, Yaron Y, Eshhar Z, Orr-Urtreger A: Multiple genes in human 20q13 chromosomal region are involved in an advanced prostate cancer xenograft. Cancer research 2002, 62(23):6803-6807.

10. Ginestier C, Cervera N, Finetti P, Esteyries S, Esterni B, Adelaide J, Xerri L, Viens P, Jacquemier J, Charafe-Jauffret $\mathrm{E}$ et al: Prognosis and gene expression profiling of 20q13-amplified breast cancers. Clinical cancer research : an official journal of the American Association for Cancer Research 2006, 12(15):4533-4544.

11. Letessier A, Sircoulomb F, Ginestier C, Cervera N, Monville F, Gelsi-Boyer V, Esterni B, Geneix J, Finetti $P$, Zemmour $C$ et al: Frequency, prognostic impact, and subtype association of 8p12, 8q24, 11q13, $12 p 13,17 q 12$, and 20q13 amplifications in breast cancers. BMC cancer 2006, 6:245.

12. Zheng SL, Xu J, Isaacs SD, Wiley K, Chang B, Bleecker ER, Walsh PC, Trent JM, Meyers DA, Isaacs WB: Evidence for a prostate cancer linkage to chromosome 20 in 159 hereditary prostate cancer families. Human genetics 2001, 108(5):430-435.

13. Tanner MM, Grenman S, Koul A, Johannsson O, Meltzer P, Pejovic T, Borg A, Isola JJ: Frequent amplification of chromosomal region 20q12-q13 in ovarian cancer. Clinical cancer research : an official journal of the American Association for Cancer Research 2000, 6(5):1833-1839.

14. Knosel T, Schluns K, Stein U, Schwabe H, Schlag PM, Dietel M, Petersen I: Genetic imbalances with impact on survival in colorectal cancer patients. Histopathology 2003, 43(4):323-331.

15. Korn WM, Yasutake T, Kuo WL, Warren RS, Collins C, Tomita M, Gray J, Waldman FM: Chromosome arm 20q gains and other genomic alterations in colorectal cancer metastatic to liver, as analyzed by comparative genomic hybridization and fluorescence in situ hybridization. Genes, chromosomes \& cancer 1999, 25(2):82-90.

16. Krackhardt AM, Witzens M, Harig S, Hodi FS, Zauls AJ, Chessia M, Barrett P, Gribben JG: Identification of tumor-associated antigens in chronic lymphocytic leukemia by SEREX. Blood 2002, 100(6):21232131. 
17. Zhang J, Cho SJ, Shu L, Yan W, Guerrero T, Kent M, Skorupski K, Chen H, Chen X: Translational repression of p53 by RNPC1, a p53 target overexpressed in lymphomas. Genes \& development 2011, 25(14):1528-1543.

18. Xue JQ, Xia TS, Liang XQ, Zhou W, Cheng L, Shi L, Wang Y, Ding Q: RNA-binding protein RNPC1: acting as a tumor suppressor in breast cancer. BMC cancer 2014, 14:322.

19. Zheng L, Zhang Z, Zhang S, Guo Q, Zhang F, Gao L, Ni H, Guo X, Xiang C, Xi T: RNA Binding Protein RNPC1 Inhibits Breast Cancer Cell Metastasis via Activating STARD13-Correlated ceRNA Network. Molecular pharmaceutics 2018, 15(6):2123-2132.

20. Cheng G, Ji C, Yang N, Meng L, Ding Y, Wei J: RNA-binding protein RBM38: Acting as a tumor suppressor in colorectal cancer. International Journal of Clinical \& Experimental Medicine 2016, 9(4):7115-7126.

21. Wampfler J, Federzoni EA, Torbett BE, Fey MF, Tschan MP: The RNA binding proteins RBM38 and DND1 are repressed in AML and have a novel function in APL differentiation. Leukemia research 2016, 41:96-102.

22. Yang $L$, Zhang $Y$, Ling $C$, Heng W: RNPC1 inhibits non-small cell lung cancer progression via regulating miR-181a/CASC2 axis. Biotechnology letters 2018, 40(3):543-550.

23. Huang W, Wei XL, Ni W, Cao M, Meng L, Yang H: The expression of RNA-binding protein RBM38 decreased in renal cell carcinoma and represses renal cancer cell proliferation, migration, and invasion. Tumour biology : the journal of the International Society for Oncodevelopmental Biology and Medicine 2017, 39(5):1010428317701635.

24. Ye J, Liang R, Bai T, Lin Y, Mai R, Wei M, Ye X, Li L, Wu F: RBM38 plays a tumor-suppressor role via stabilizing the p53-mdm2 loop function in hepatocellular carcinoma. Journal of experimental \& clinical cancer research : CR 2018, 37(1):212.

25. Zhang J, Xu E, Ren C, Yang HJ, Zhang Y, Sun W, Kong X, Zhang W, Chen M, Huang E et al: Genetic Ablation of Rbm38 Promotes Lymphomagenesis in the Context of Mutant p53 by Downregulating PTEN. Cancer research 2018, 78(6):1511-1521.

26. Lin QY, Yin HL: RBM38 induces SIRT1 expression during hypoxia in non-small cell lung cancer cells by suppressing MIR34A expression. Biotechnology letters 2020, 42(1):35-44.

27. Yu X, Wang W, Lin X, Zheng X, Yang A: Roles of ZEB2 and RBM38 in liver cancer stem cell proliferation. Journal of BUON : official journal of the Balkan Union of Oncology 2020, 25(3):13901394.

28. Ding Z, Yang HW, Xia TS, Wang B, Ding Q: Integrative genomic analyses of the RNA-binding protein, RNPC1, and its potential role in cancer prediction. International journal of molecular medicine 2015, 36(2):473-484.

29. Zhou XJ, Wu J, Shi L, Li XX, Zhu L, Sun X, Qian JY, Wang Y, Wei JF, Ding Q: PTEN expression is upregulated by a RNA-binding protein RBM38 via enhancing its mRNA stability in breast cancer. Journal of experimental \& clinical cancer research : CR 2017, 36(1):149. 
30. Bolanos-Garcia VM: Aurora kinases. The international journal of biochemistry \& cell biology 2005 , 37(8):1572-1577.

31. Ducat $D$, Zheng $Y$ : Aurora kinases in spindle assembly and chromosome segregation. Experimental cell research 2004, 301(1):60-67.

32. Tang A, Gao K, Chu L, Zhang R, Yang J, Zheng J: Aurora kinases: novel therapy targets in cancers. Oncotarget 2017, 8(14):23937-23954.

33. Santaguida S, Amon A: Short- and long-term effects of chromosome mis-segregation and aneuploidy. Nature reviews Molecular cell biology 2015, 16(8):473-485.

34. Hindriksen S, Meppelink A, Lens SM: Functionality of the chromosomal passenger complex in cancer. Biochemical Society transactions 2015, 43(1):23-32.

35. Gonzalez-Loyola A, Fernandez-Miranda G, Trakala M, Partida D, Samejima K, Ogawa H, Canamero M, de Martino A, Martinez-Ramirez A, de Carcer G et al: Aurora B Overexpression Causes Aneuploidy and p21Cip1 Repression during Tumor Development. 2015, 35(20):3566-3578.

36. Goldenson B, Crispino JD: The aurora kinases in cell cycle and leukemia. Oncogene 2015, 34(5):537545.

37. Smith SL, Bowers NL, Betticher DC, Gautschi O, Ratschiller D, Hoban PR, Booton R, Santibáñez-Koref MF, Heighway J: Overexpression of aurora B kinase (AURKB) in primary non-small cell lung carcinoma is frequent, generally driven from one allele, and correlates with the level of genetic instability. British journal of cancer 2005, 93(6):719-729.

38. Chieffi P, Troncone G, Caleo A, Libertini S, Linardopoulos S, Tramontano D, Portella G: Aurora B expression in normal testis and seminomas. The Journal of endocrinology 2004, 181(2):263-270.

39. Sorrentino R, Libertini S, Pallante PL, Troncone G, Palombini L, Bavetsias V, Spalletti-Cernia D, Laccetti P, Linardopoulos S, Chieffi P et al: Aurora B overexpression associates with the thyroid carcinoma undifferentiated phenotype and is required for thyroid carcinoma cell proliferation. The Journal of clinical endocrinology and metabolism 2005, 90(2):928-935.

40. Hegyi K, Egervári K, Sándor Z, Méhes G: Aurora kinase B expression in breast carcinoma: cell kinetic and genetic aspects. Pathobiology : journal of immunopathology, molecular and cellular biology 2012, 79(6):314-322.

41. Honma K, Nakanishi R, Nakanoko T, Ando K, Saeki H, Oki E, limori M, Kitao H, Kakeji Y, Maehara Y: Contribution of Aurora-A and -B expression to DNA aneuploidy in gastric cancers. Surgery today 2014, 44(3):454-461.

42. Nie M, Wang Y, Yu Z, Li X, Deng Y, Wang Y, Yang D, Li Q, Zeng X, Ju J et al: AURKB promotes gastric cancer progression via activation of CCND1 expression. Aging 2020, 12(2):1304-1321.

43. Shi L, Xia TS, Wei XL, Zhou W, Xue J, Cheng L, Lou P, Li C, Wang Y, Wei JF et al: Estrogen receptor (ER) was regulated by RNPC1 stabilizing mRNA in ER positive breast cancer. Oncotarget 2015, 6(14):12264-12278.

44. Hotte GJ, Linam-Lennon N, Reynolds JV, Maher SG: Radiation sensitivity of esophageal adenocarcinoma: the contribution of the RNA-binding protein RNPC1 and p21-mediated cell cycle 
arrest to radioresistance. Radiation research 2012, 177(3):272-279.

45. Cho SJ, Zhang J, Chen X: RNPC1 modulates the RNA-binding activity of, and cooperates with, HuR to regulate p21 mRNA stability. Nucleic acids research 2010, 38(7):2256-2267.

46. Yan W, Zhang J, Zhang Y, Jung YS, Chen X: p73 expression is regulated by RNPC1, a target of the p53 family, via mRNA stability. Molecular and cellular biology 2012, 32(13):2336-2348.

47. Cho SJ, Jung YS, Zhang J, Chen X: The RNA-binding protein RNPC1 stabilizes the mRNA encoding the RNA-binding protein HuR and cooperates with HuR to suppress cell proliferation. The Journal of biological chemistry 2012, 287(18):14535-14544.

48. Brown DA, Lindmark F, Stattin P, Balter K, Adami HO, Zheng SL, Xu J, Isaacs WB, Gronberg H, Breit SN et al: Macrophage inhibitory cytokine 1: a new prognostic marker in prostate cancer. Clinical cancer research : an official journal of the American Association for Cancer Research 2009, 15(21):66586664.

49. Wu J, Zhou XJ, Sun X, Xia TS, Li XX, Shi L, Zhu L, Zhou WB, Wei JF, Ding Q: RBM38 is involved in TGF-beta-induced epithelial-to-mesenchymal transition by stabilising zonula occludens-1 mRNA in breast cancer. British journal of cancer 2017, 117(5):675-684.

50. Lou P, Li C, Shi L, Xia TS, Zhou W, Wu J, Zhou X, Li X, Wang Y, Wei JF et al: RNPC1 enhances progesterone receptor functions by regulating its mRNA stability in breast cancer. Oncotarget 2017, 8(10):16387-16400.

51. Zhang J, Jun Cho S, Chen X: RNPC1, an RNA-binding protein and a target of the p53 family, regulates p63 expression through mRNA stability. Proceedings of the National Academy of Sciences of the United States of America 2010, 107(21):9614-9619.

52. Jiang Y, Xu E, Zhang J, Chen M, Flores E, Chen X: The Rbm38-p63 feedback loop is critical for tumor suppression and longevity. 2018.

53. Zhang Y, Feng X, Sun W, Zhang J, Chen X: Serine 195 phosphorylation in the RNA-binding protein Rbm38 increases p63 expression by modulating Rbm38's interaction with the Ago2-miR203 complex. The Journal of biological chemistry 2019, 294(7):2449-2459.

54. Yan W, Zhang Y, Chen X: TAp63gamma and DeltaNp63gamma are regulated by RBM38 via mRNA stability and have an opposing function in growth suppression. Oncotarget 2017, 8(45):7832778339.

55. Li XX, Shi L, Zhou XJ, Wu J, Xia TS, Zhou WB, Sun X, Zhu L, Wei JF, Ding Q: The role of c-Myc-RBM38 loop in the growth suppression in breast cancer. Journal of experimental \& clinical cancer research : CR 2017, 36(1):49.

56. Xu E, Zhang J, Chen X: MDM2 expression is repressed by the RNA-binding protein RNPC1 via mRNA stability. Oncogene 2013, 32(17):2169-2178.

57. Bloomfield M, Duesberg P: Is cancer progression caused by gradual or simultaneous acquisitions of new chromosomes? Molecular cytogenetics 2018, 11:4.

58. Nishimura S, Oki E: High ubiquitin-specific protease 44 expression induces DNA aneuploidy and provides independent prognostic information in gastric cancer. 2017, 6(6):1453-1464. 
59. Hanahan D, Weinberg RA: Hallmarks of cancer: the next generation. Cell 2011, 144(5):646-674.

60. Ritter A, Sanhaji M, Friemel A, Roth S, Rolle U, Louwen F, Yuan J: Functional analysis of phosphorylation of the mitotic centromere-associated kinesin by Aurora B kinase in human tumor cells. Cell cycle (Georgetown, Tex) 2015, 14(23):3755-3767.

\section{Tables}

Table 1: The association of RNPC1 expression and clinicopathological characteristics of gastric cancer. 


\begin{tabular}{|c|c|c|c|c|}
\hline \multirow{2}{*}{$\begin{array}{c}\text { Clinicopathological } \\
\text { characteristics }\end{array}$} & \multirow[t]{2}{*}{ No. of cases } & \multicolumn{2}{|c|}{ RNPC1 expression } & \multirow[t]{2}{*}{$P$} \\
\hline & & $\operatorname{Low}(\%)$ & High(\%) & \\
\hline \multicolumn{5}{|l|}{ gender } \\
\hline Male & 44 & $23(52.27)$ & $21(47.73)$ & \\
\hline Female & 41 & 19(46.34) & $22(53.66)$ & 0.666 \\
\hline \multicolumn{5}{|l|}{ Pathological grade } \\
\hline I & 6 & $4(66.67)$ & $2(33.33)$ & \\
\hline II & 49 & $28(57.14)$ & $21(42.86)$ & \\
\hline III & 30 & 10(33.33) & $20(66.67)$ & 0.083 \\
\hline \multicolumn{5}{|l|}{ Age } \\
\hline$<=60$ & 41 & 18(43.90) & $23(56.10)$ & \\
\hline$>60$ & 44 & $24(54.55)$ & $20(45.45)$ & 0.388 \\
\hline \multicolumn{5}{|l|}{ TNM stage } \\
\hline $1+\|$ & 51 & $30(58.82)$ & $21(41.18)$ & \\
\hline$\nabla+\square$ & 34 & 12(35.30) & $22(64.70)$ & 0.046 \\
\hline \multicolumn{5}{|l|}{ Lymph node metastasis } \\
\hline- & 27 & $17(62.96)$ & $10(37.04)$ & \\
\hline+ & 58 & $25(43.10)$ & $33(56.90)$ & 0.106 \\
\hline \multicolumn{5}{|l|}{ Cancer type } \\
\hline Gastric cancer tissues & 85 & $42(49.41)$ & $43(50.59)$ & \\
\hline tumor-adjacent normal tissues & 26 & 19(73.07) & $7(26.92)$ & 0.034 \\
\hline \multicolumn{5}{|l|}{ AURKB expression } \\
\hline Low & 34 & $22(64.71)$ & 12(35.29) & \\
\hline High & 51 & $20(39.22)$ & $31(60.78)$ & 0.021 \\
\hline
\end{tabular}

\section{Figures}


A

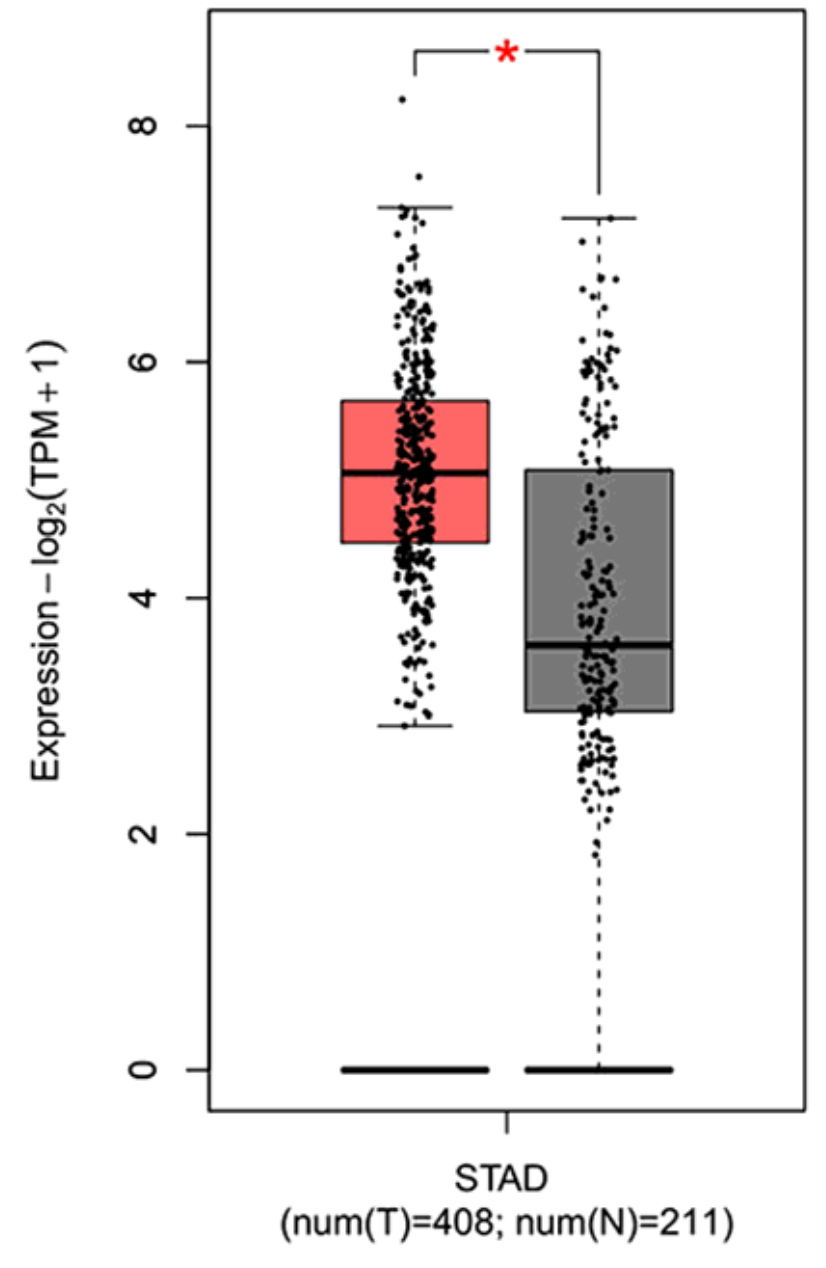

B

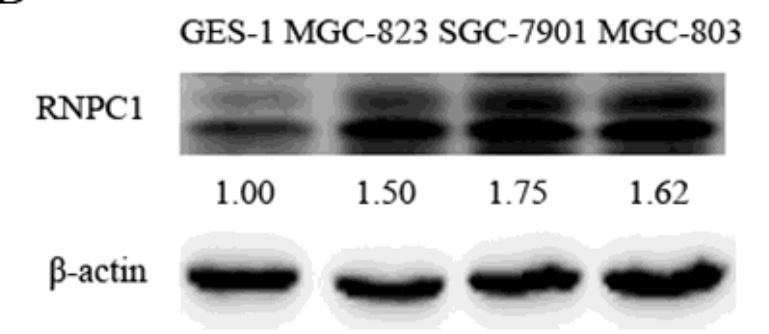

$\mathrm{C}$

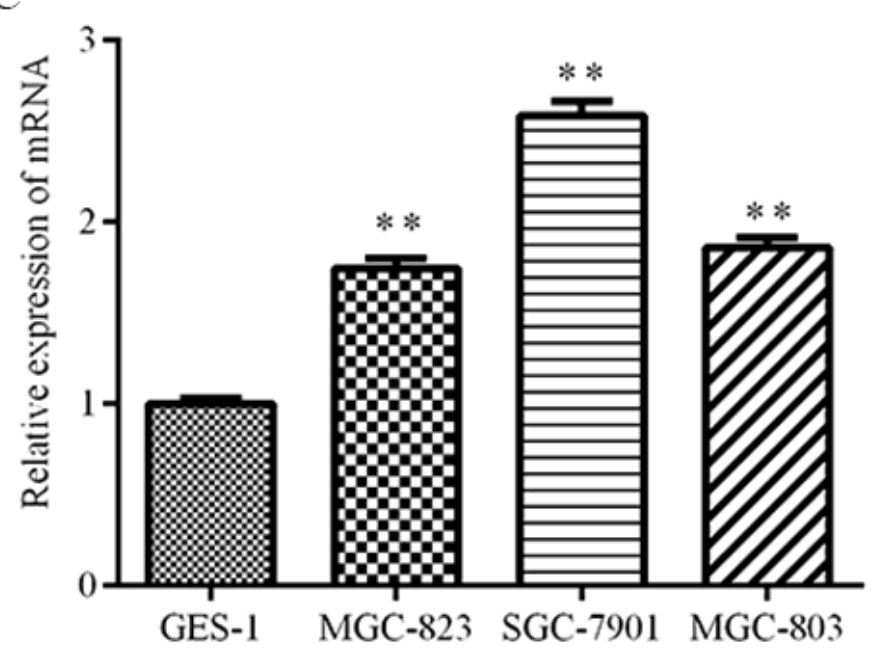

\section{Figure 1}

RNPC1 was elevated in gastric cancer tissues and cells. (A) According to the TCGA database, RNPC1 was significantly upregulated in gastric cancer tissues compared with normal tissues. $(B, C)$ The mRNA and protein expression levels of RNPC1 were detected by qRT-PCR and western blot analysis in human normal stomach cells line and gastric cancer cell lines. 
A

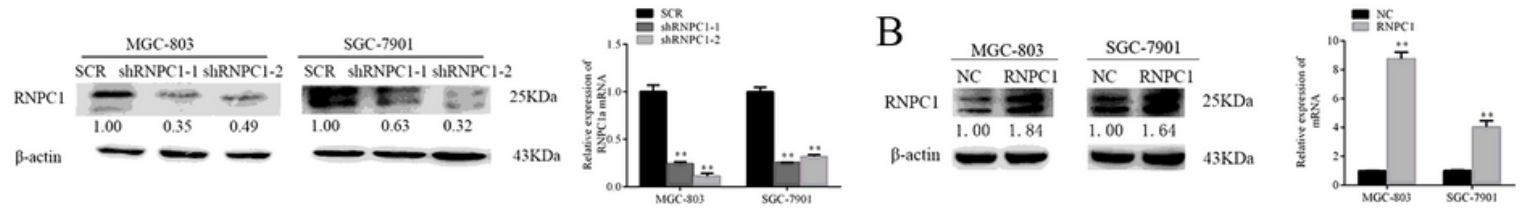

C

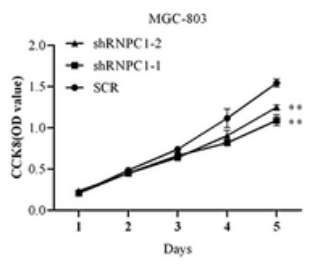

E
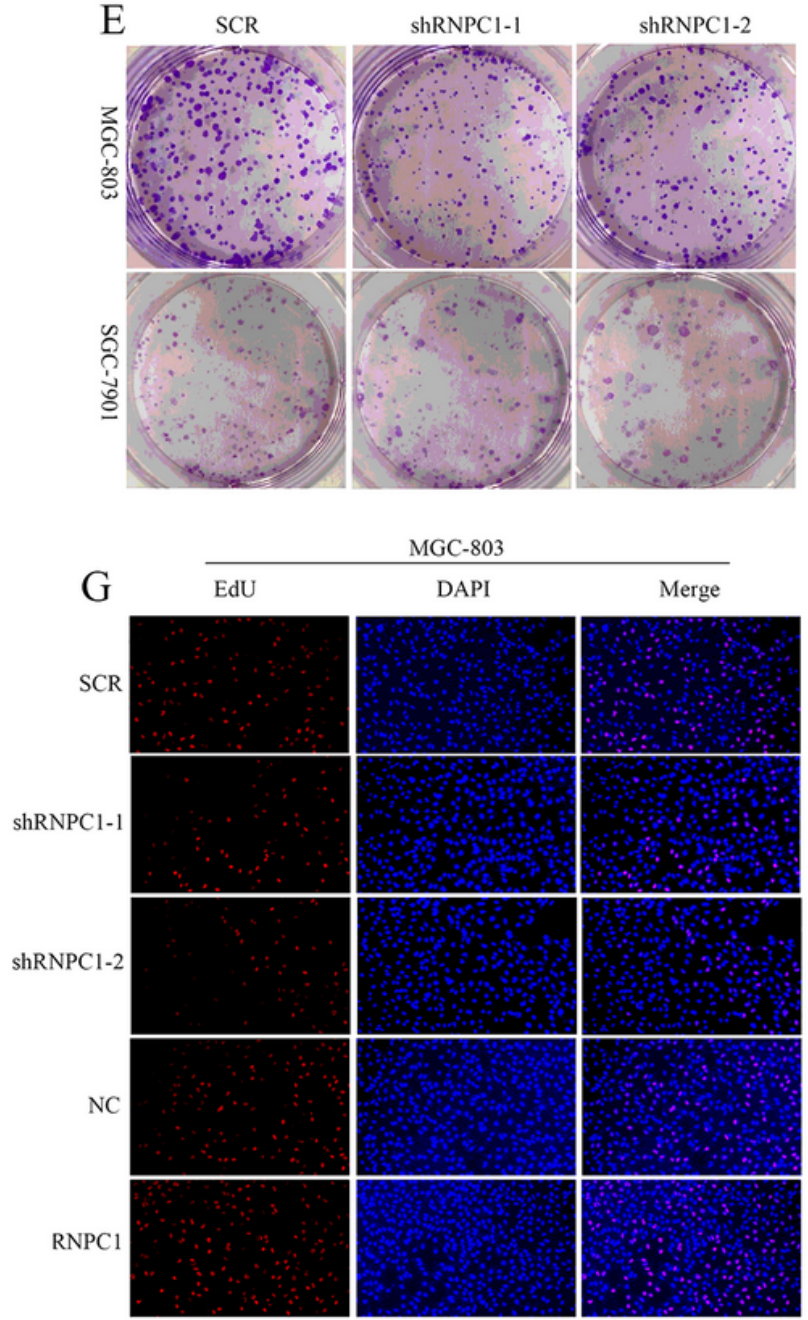

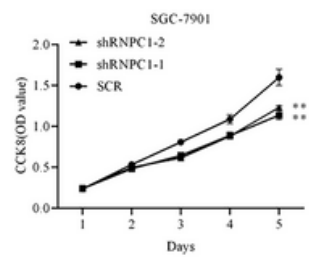

D

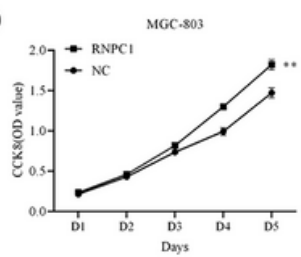

F

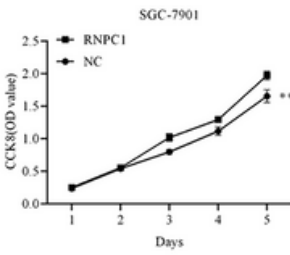

RNPC1
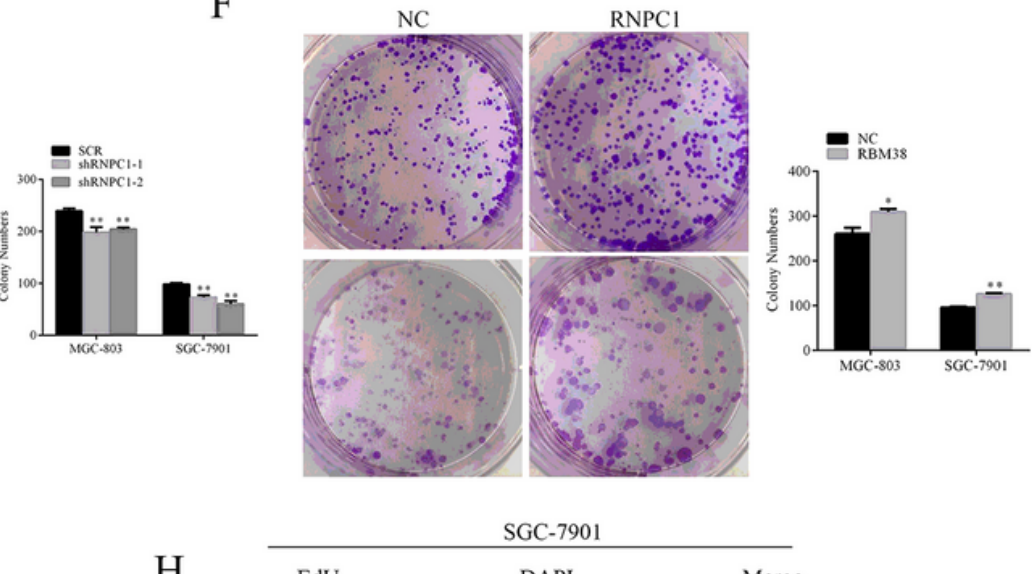

$\mathrm{H}$
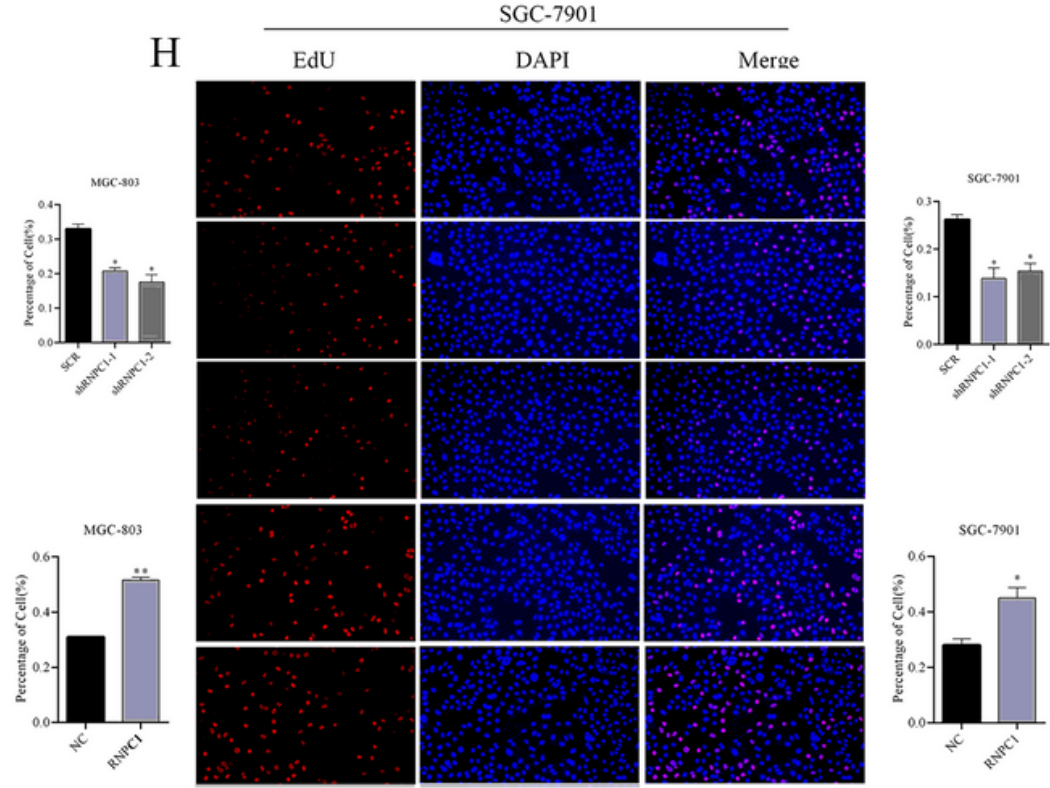

\section{Figure 2}

RNPC1 promoted the proliferation of gastric cancer cells in vitro. (A, B) Western blot and qRT-PCR were used to verify the efficiency of RNPC1 knockdown and overexpression in gastric cancer cell line(MGC-803 and SGC-7901). (C, D)The proliferation of gastric cancer cells were measured with CCK-8 assays. Cell proliferation was inhibited in RNPC1 knockdown (shRNPC1-1, shRNPC1-2) compared with the control (SCR) in gastric cancer cell lines MGC-803 and SGC-7901. Whereas, RNPC1 overexpression (RNPC1) promoted the cell proliferation compared with the control (NC) cells. (E, F) Colony formation assays 
showed that RNPC1 knockdown inhibited the colony formation ability of MGC-803 and SGC-7901, while RNPC1 overexpression increased. Representative photographs (left) and quantification (right) were shown. $(\mathrm{G}, \mathrm{H})$ The percentages of EdU positive cells of MGC-803 and SGC-7901 were examined by EdU assay. Date represented the mean $\pm S D$ from three independent experiments $\left({ }^{*} P<0.05, * * P<0.01\right)$.
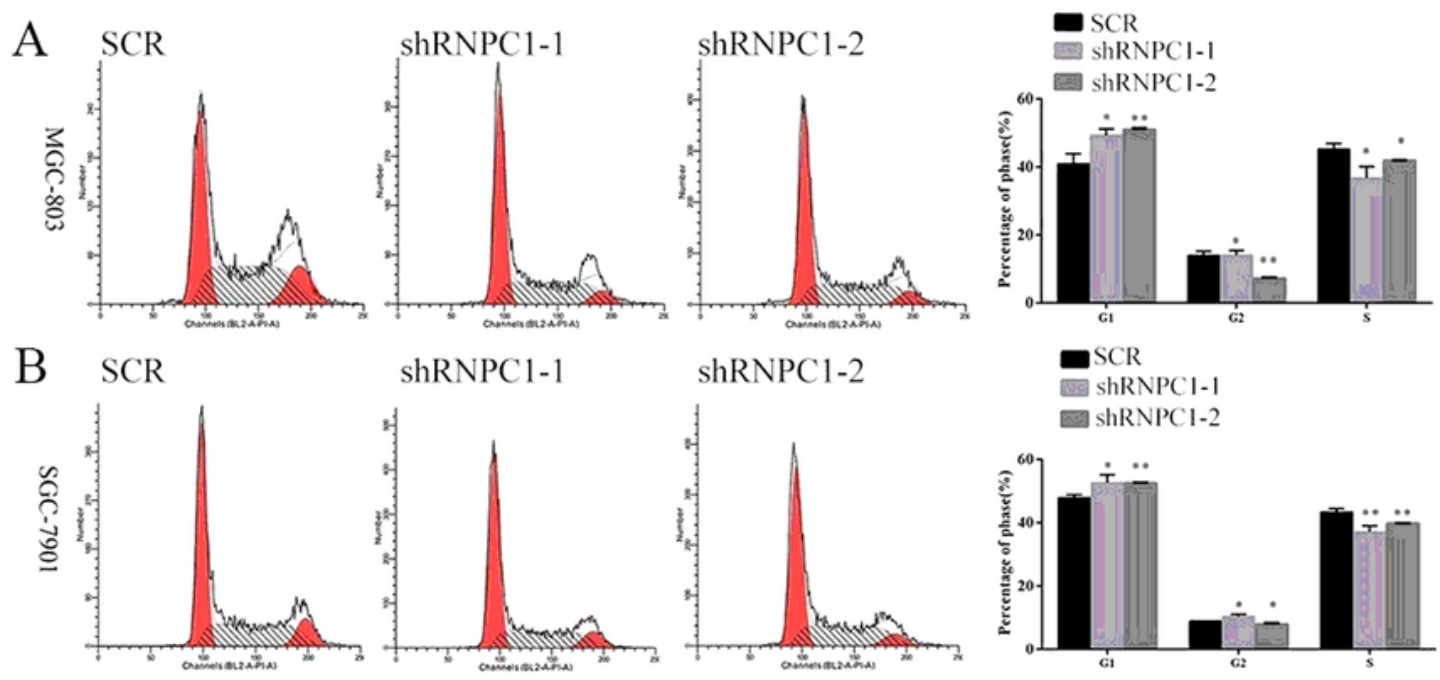

- $\mathrm{SCR}$

훔 shNPCl-1

shRNPCl-2
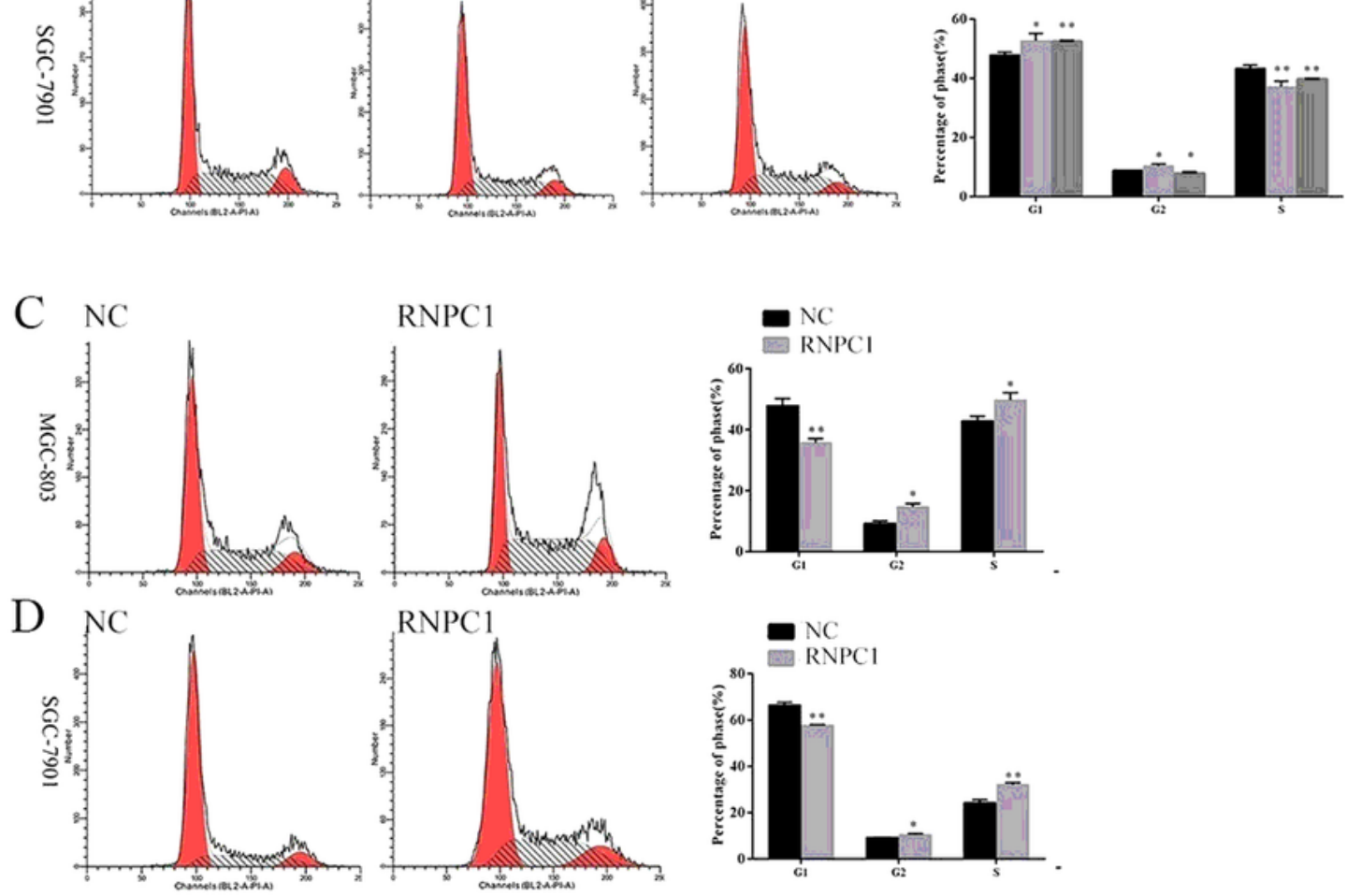

$\mathrm{E}$
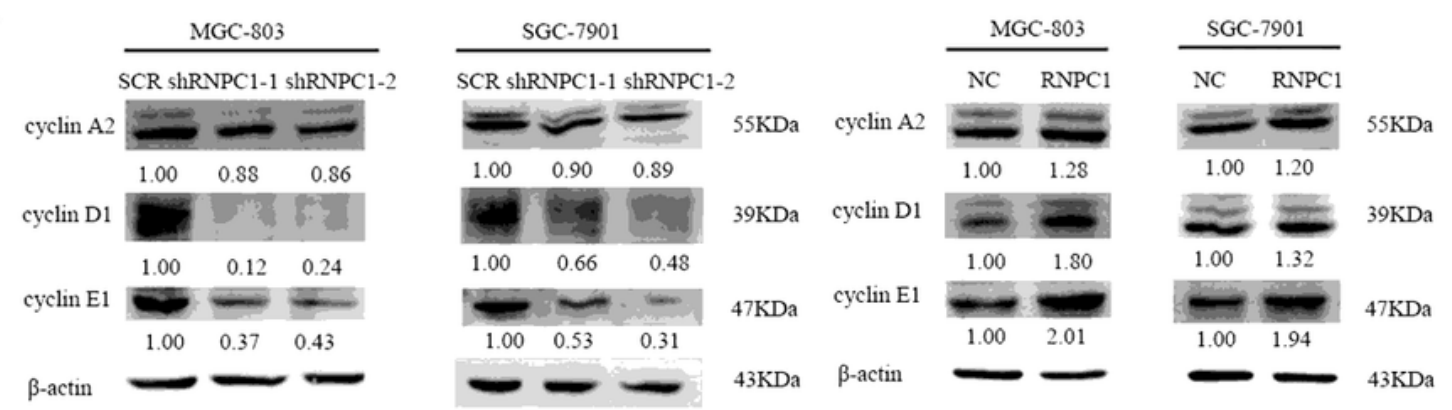

Figure 3 
Effect of RNPC1 on cell cycle.(A, B,C,D) Cell cycle progression was measured by flow cytometry. An increased percentage of cells in $\mathrm{G} 1$ phase occurred in RNPC1 knockdown cells while RNPC1 overexpression had opposite effects. The histogram indicated the percentage of cells in G1, S, G2 phase. Representative photographs (left) and quantification (right) were shown.(E) Cell cycle phase-specific cyclins. RNPC1 knockdown down-regulated the protein expression of cyclin D1, cyclin E1 in gastric cancer cells(MGC-803, and SGC-7901), but not influence the cyclin A2 expression. While RNPC1 overexpression positively regulated the cyclin D1,cyclin E1 expression without obviously changes in cycline A2 expression.Date represented the mean $\pm S D$ from three independent experiments $\left({ }^{\star} P<0.05,{ }^{*} P<0.01\right)$.

A

SGC-7901-SCR

SGC-7901-shRNPC1
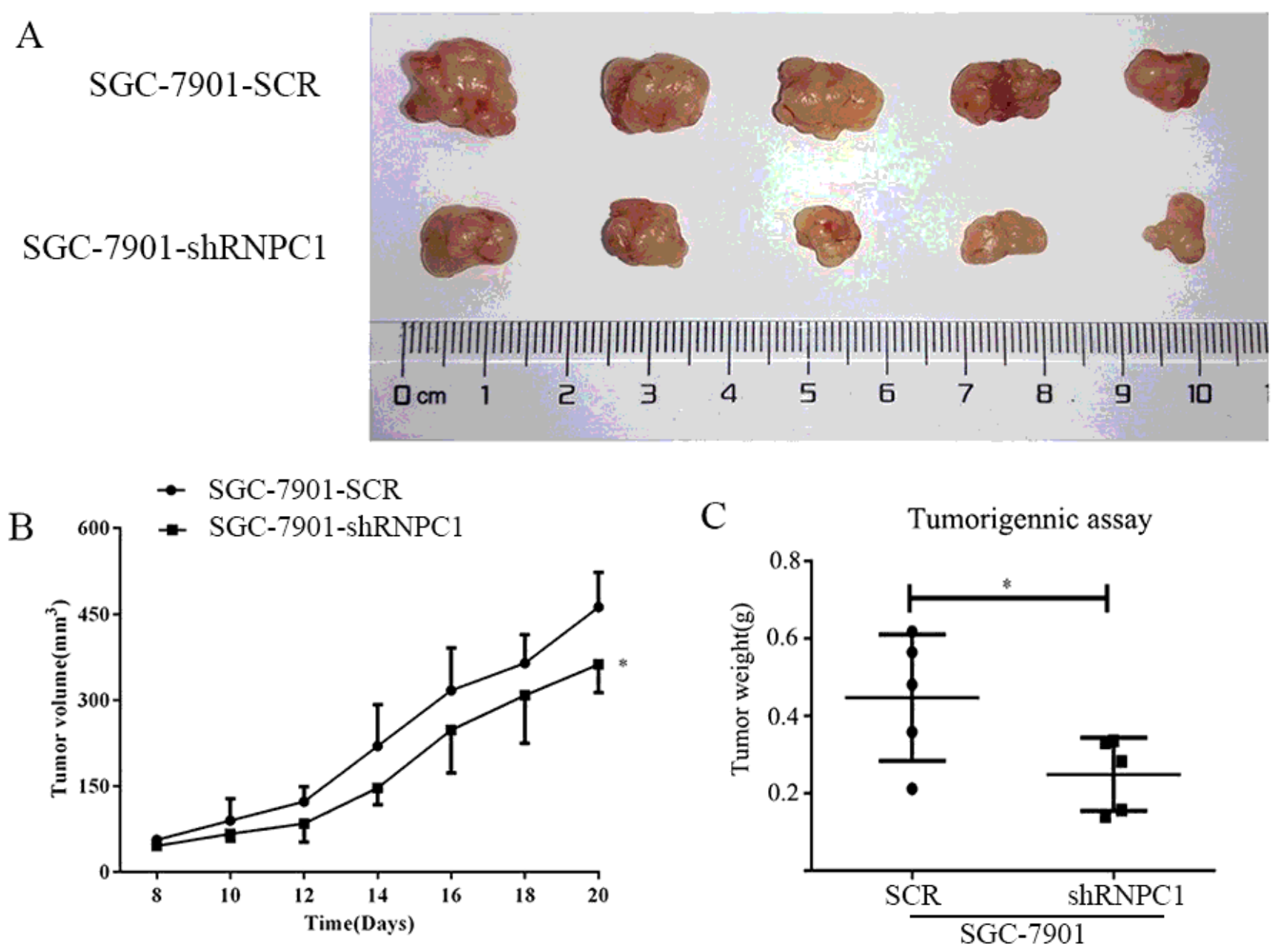

Figure 4

RNPC1 promoted tumorigenesis in nude mice in vivo. (A) Representative photographs of tumor formation of xenograft in nude mice $(n=5)$ injected with gastric cancer cell lines SGC-7901-SCR and SGC-7901shRNPC1 for three weeks. $(B, C)$ Tumor volume and weight were measured at the indicated weeks after mice were transplanted. $\left({ }^{\star} \mathrm{P}<0.05,{ }^{\star} * \mathrm{P}<0.01\right)$. 


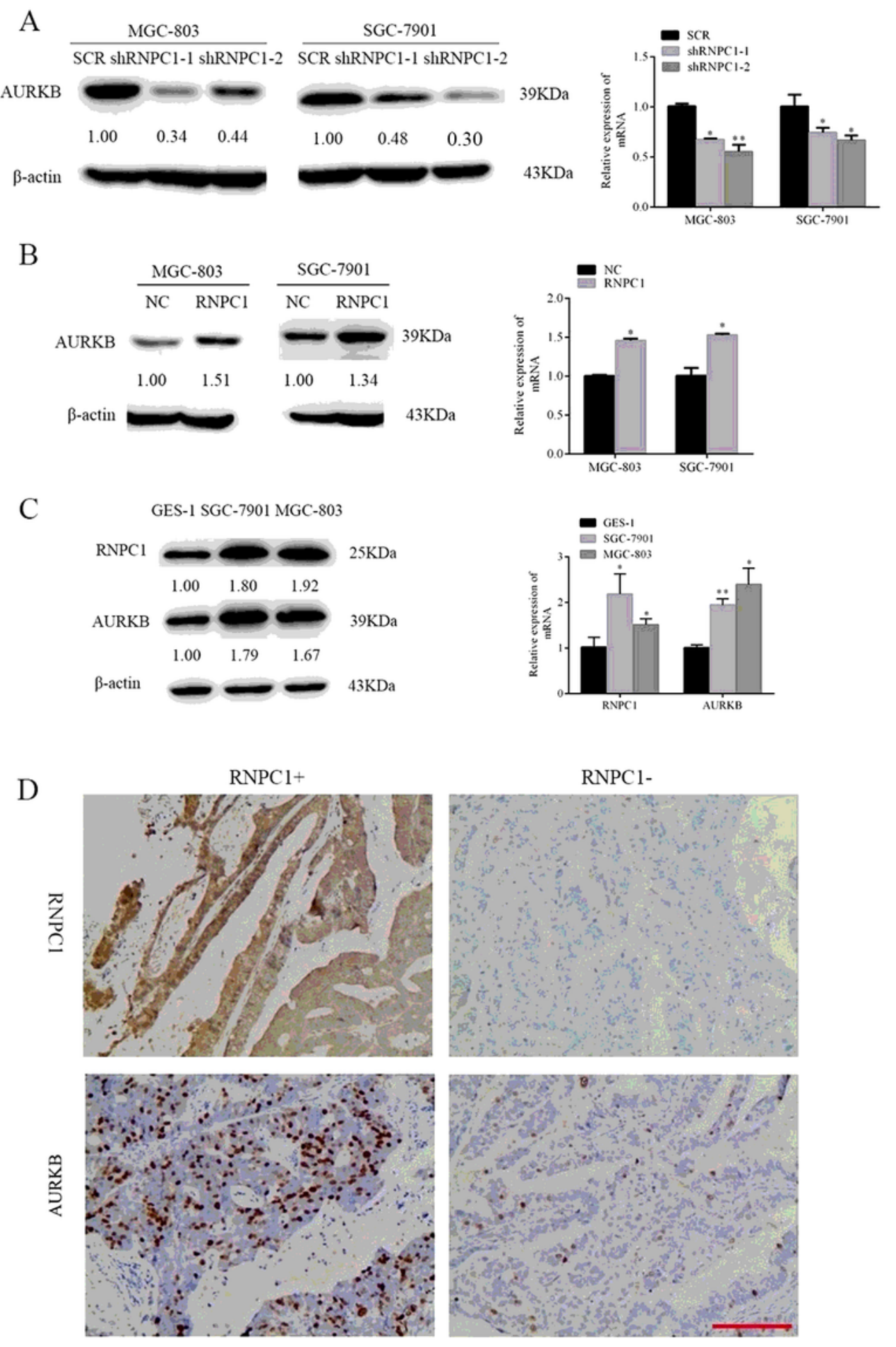

\section{Figure 5}

RNPC1 expression was positively correlated with AURKB in gastric cancer cells and tissues. (A, B) Western blot and qRT-PCR were used to measure the expression of AURKB in RNPC1 knockdown and overexpresion gastric cancer cell lines(MGC-803 and SGC-7901).The protein and mRNA expression of AURKB was decreased in RNPC1 knockdown cells. Meanwhile, AURKB expression was obviously increased in RNPC1 overexpression cells. (C)The relative expression of RNPC1 and AURKB in the GES-1, 
MGC-803 and SGC-7901 cell lines. (D) IHC analysis of RNPC1 and AURKB in gastric cancer tissues at 100× magnifcation. RNPC1 positive gastric cancer tissues expressed high level of AURKB; RNPC1 negative gastric cancer expressed low level of AURKB, representative photographs were shown. PI. Scale bar indicated $50 \mu \mathrm{m}$. ( $\left.{ }^{*} \mathrm{P}<0.05, * * \mathrm{P}<0.01\right)$.

A

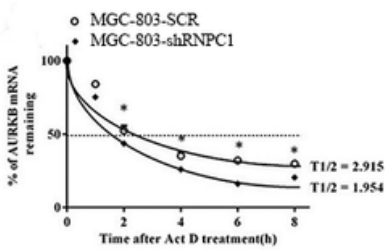

$\mathrm{C}$

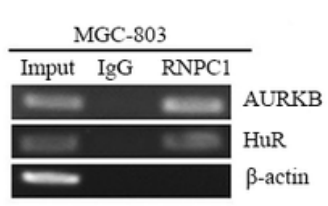

SGC-7901
Imput $\quad$ IgG RNPC1

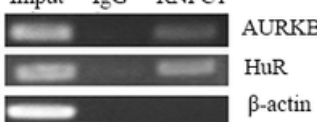

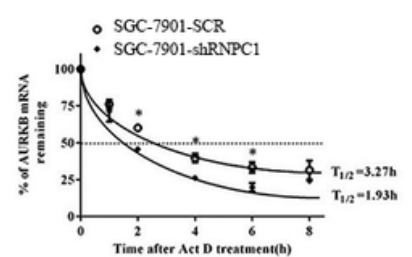
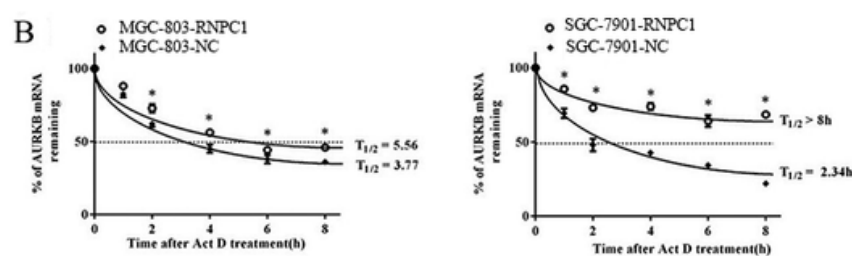

D $\frac{\text { AURKB }}{-++ \text { RNPC1 }}$

+++ Biotin-labled probe

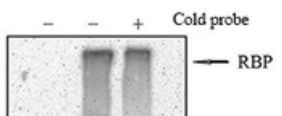

E

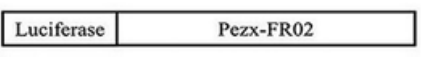

\begin{tabular}{|l|l|}
\hline Luciferase & AURKB 3'-UTR(1085 to 1224) \\
\hline
\end{tabular}

mutation

\begin{tabular}{|l|l|}
\hline Luciferase & AURKB 3'-U \\
\hline
\end{tabular}

MGC-803

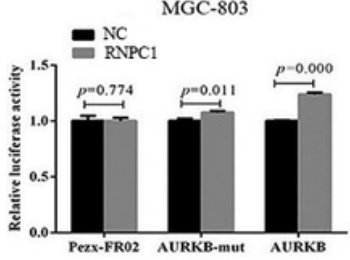

SGC-7901

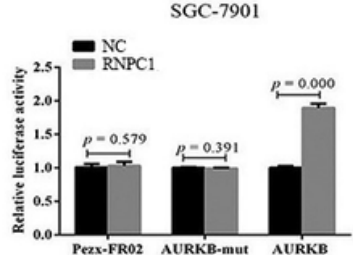

Figure 6

RNPC1 could bind to AURKB mRNA directly and regulated its mRNA stability. $(A, B)$ The gastric cancer cell lines were treated with $5 \mu \mathrm{g} / \mathrm{ml}$ Act $D$ for $0,1,2,4,6,8 \mathrm{~h}$. The relative quantification was calculated by the $2-\triangle \triangle \mathrm{Ct}$ method and normalized based on $\beta$-actin. The half-life of AURKB mRNA decreased after RNPC1 knockdown in MGC-803 and SGC-7901. While the half-life of AURKB mRNA was enhanced by RNPC1 overexpression in MGC-803 and SGC-7901. (C)RNPC1 could bind to AURKB mRNA directly. MGC-803 and SGC-7901 cell lysates were immunoprecipiated with RNPC1 and control IgG antibodies followed by RTPCR and qRT-PCR, measuring the transcript levels of AURKB, HuR and $\beta$-actin within RNPC1 or IgG immunocompleses. (D) RNPC1 bound to the AREs of AURKB mRNA 3'-UTR. REMSA was performed by mixing bio-UTP labelled probe with RNPC1 protein. (E)Luciferase activity in MGC-803 and SGC-7901 RNPC1 overexpression (RNPC1) and control (NC) cells co-transfected with region AURKB 3'-UTR,mutation AURKB 3'-UTR or empty luciferase reports. The relative luciferase activity of reporter carrying AURKB 3'UTR was increased by RNPC1 in MGC-803 and SGC-7901, The relative luciferase activity was calculated as a ratio of luciferase activity induced by RNPC1 divided by that induced by an empty vector (mean \pm $S D),\left({ }^{*}<<0.05,{ }^{\star} * P<0.01\right)$. 
A

AZD1152-HQPA

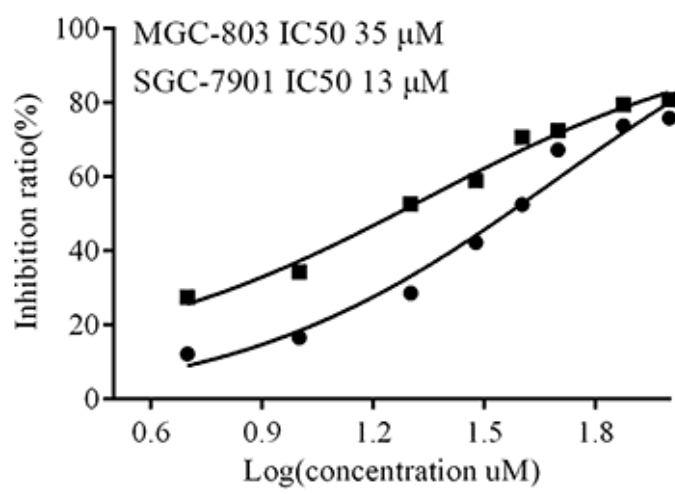

C

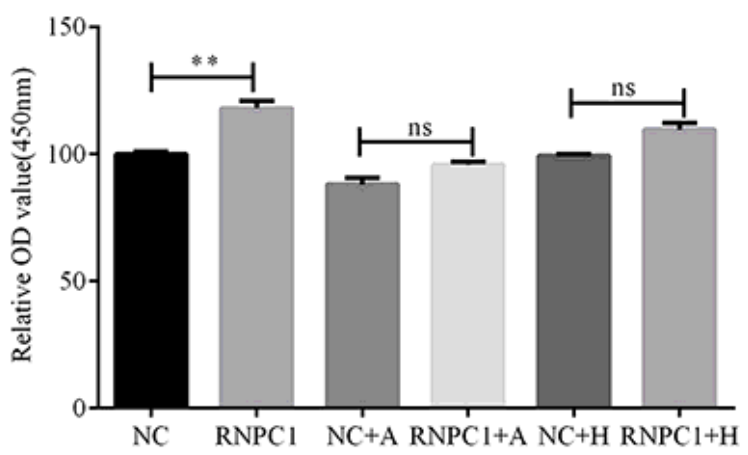

E

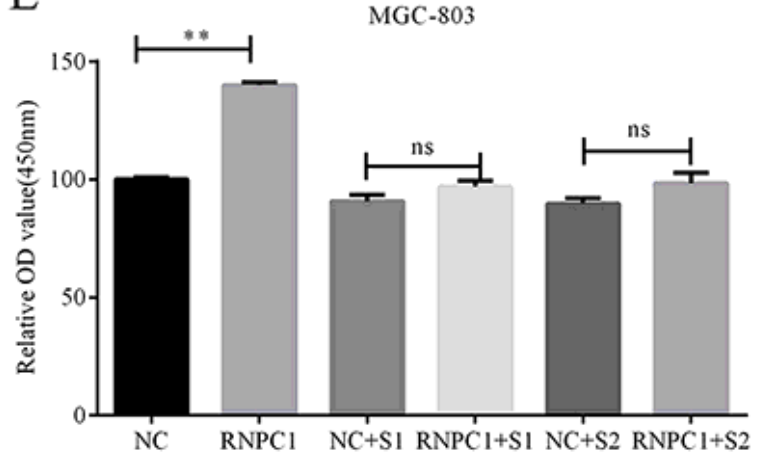

B

Hesperidin

MGC-803

SGC-7901

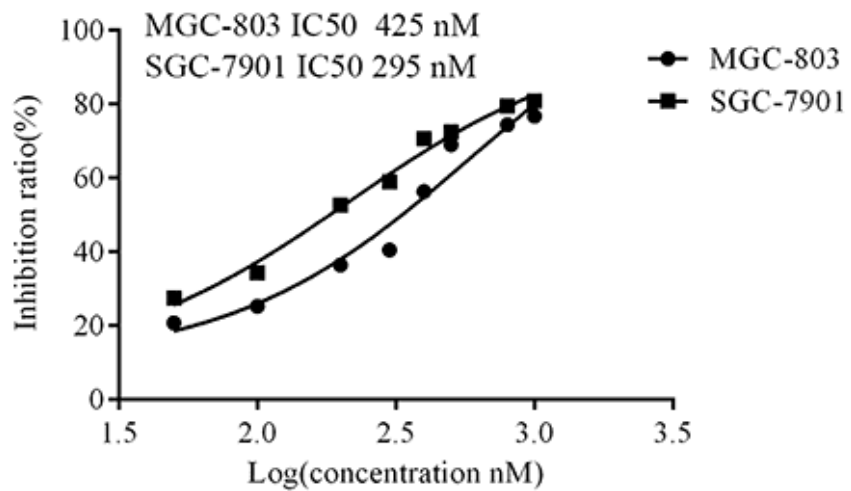

D

SGC-790I

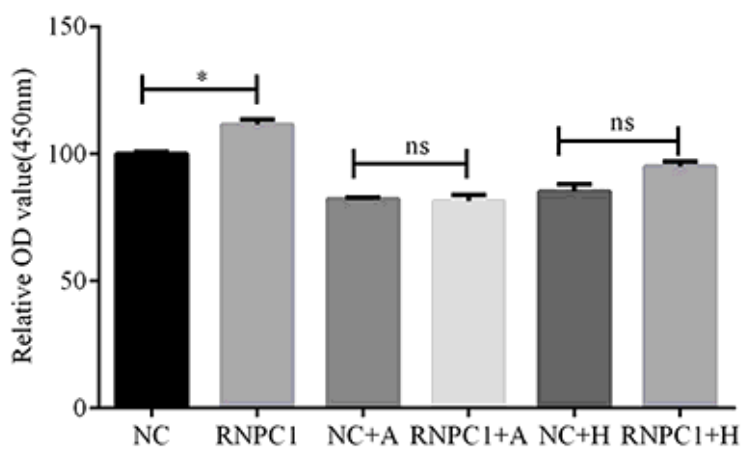

F

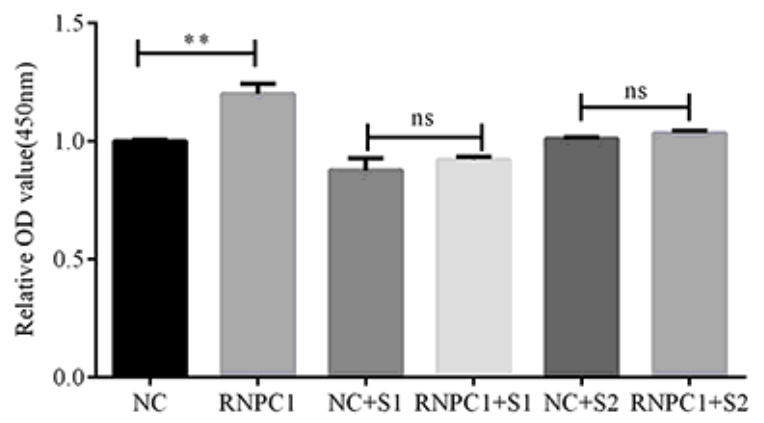

Figure 7

AURKB inhibitors and AURKB interference and reversed the proliferation induced by RNPC1 in gastric cancer cells. (A,B) The IC50 of the AURKB inhibitors(AZD1152-HQPA and hesperadin ) was explored by CCK-8 in gastric cancer cells (MGC-803, SGC-7901). (C,D) The proliferation of RNPC1 overexpress gastric cancer cells was decreased by treating with AURKB inhibitors(AZD1152-HQPA and hesperadin).(E,F) The proliferation of RNPC1 overexpress gastric cancer cells was also decreased by transfecting with siRNA(AURKB-S1, AURKB-S2), (*P<0.05, **P<0.01), nsP $₫ 0.05)$. 

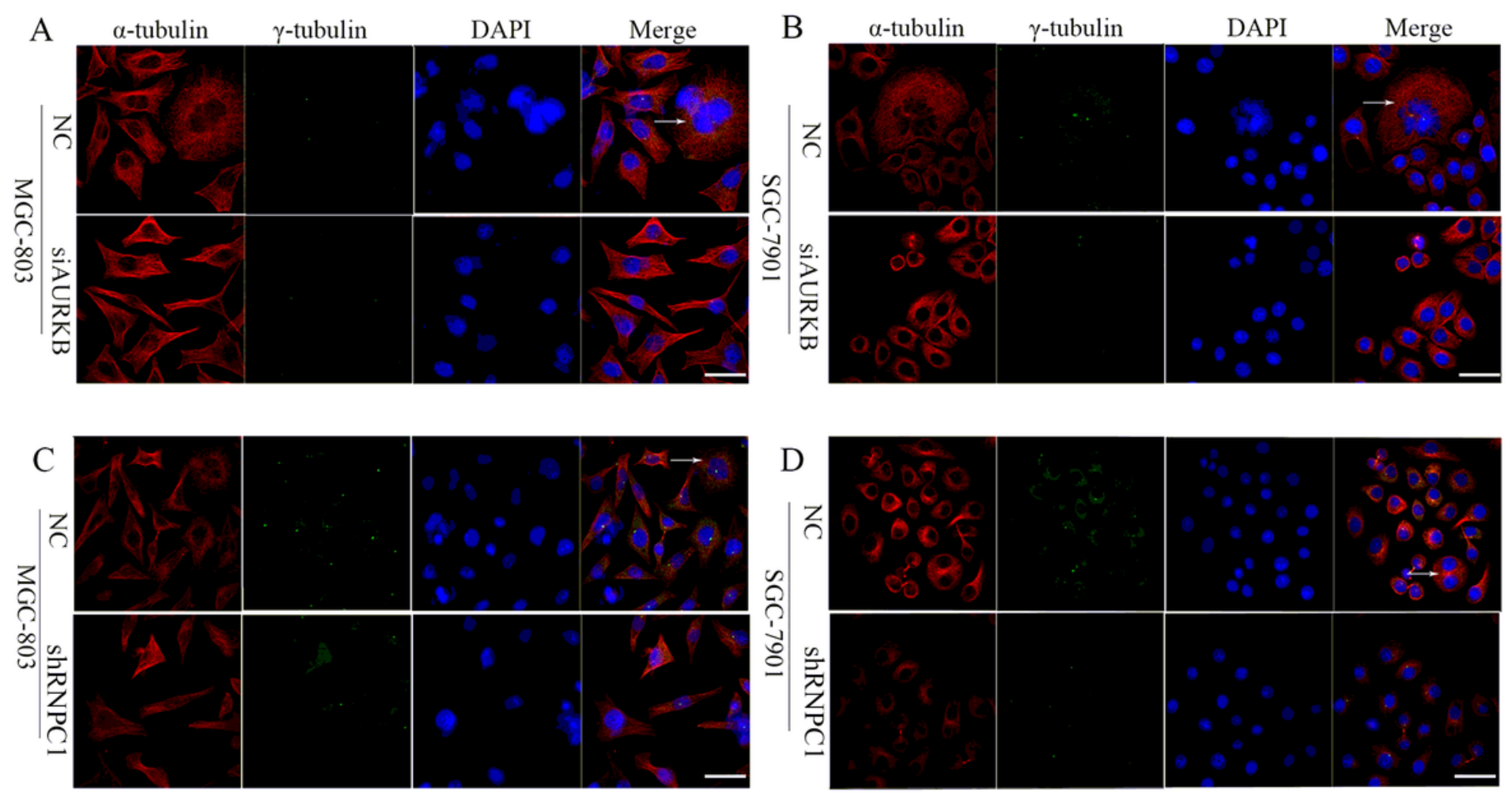

\section{Figure 8}

RNPC1 induced abnormal mitotic division by regulate AURKB. The immunofluorescence staining was used to explore the polyploidy induced by RNPC1 and AURKB. (A, B) The control cells(NC) showed more multipolar spindle or centrosome and multinucleated cells compared with the gastric cancer cells transfected with siAURKB.(C,D)The gastric cancer cells transfected with siRNPC1 showed less multipolar spindle or centrosome and multinucleated cells compared with control(NC) cells. Red represented atubulin staining, green represented $y$-tubulin staining, blue signals represented nuclear DNA staining with DAPI. Immunofluorescence staining at 400X, scale bar represents $50 \mu \mathrm{m}$.

\section{Supplementary Files}

This is a list of supplementary files associated with this preprint. Click to download.

- supplementarymaterial.docx 